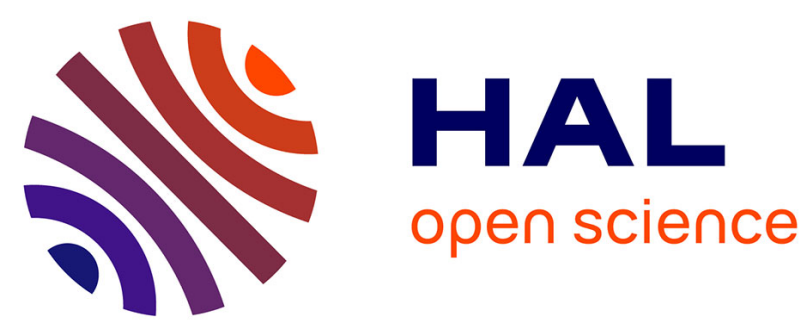

\title{
Multisatellite observations of an intensified equatorial ionization anomaly in relation to the northern Sumatra earthquake of March 2005
}

\author{
K Ryu, E Lee, J.S. Chae, Michel Parrot, K.-I Oyama
}

\section{- To cite this version:}

K Ryu, E Lee, J.S. Chae, Michel Parrot, K.-I Oyama. Multisatellite observations of an intensified equatorial ionization anomaly in relation to the northern Sumatra earthquake of March 2005. Journal of Geophysical Research Space Physics, 2014, 119, pp.4767-4785. 10.1002/2013JA019685 . insu01174156

HAL Id: insu-01174156

https://hal-insu.archives-ouvertes.fr/insu-01174156

Submitted on 8 Jul 2015

HAL is a multi-disciplinary open access archive for the deposit and dissemination of scientific research documents, whether they are published or not. The documents may come from teaching and research institutions in France or abroad, or from public or private research centers.
L'archive ouverte pluridisciplinaire HAL, est destinée au dépôt et à la diffusion de documents scientifiques de niveau recherche, publiés ou non, émanant des établissements d'enseignement et de recherche français ou étrangers, des laboratoires publics ou privés. 


\section{Journal of Geophysical Research: Space Physics}

\author{
RESEARCH ARTICLE \\ 10.1002/2013JA019685 \\ Key Points: \\ - We report ionospheric disturbance \\ in relation to the northern \\ Sumatra earthquake \\ - Intensified EIA related to the large \\ earthquake observed by DEMETER \\ and CHAMP \\ - We proposed a view of \\ seismo-ionospheric coupling in the \\ equator region
}

Correspondence to:

K. Ryu,

kwangsun@kaist.ac.kr

\section{Citation:}

Ryu, K., E. Lee, J. S. Chae, M. Parrot, and K.-I. Oyama (2014), Multisatellite observations of an intensified equatorial ionization anomaly in relation to the northern Sumatra earthquake of March 2005, J. Geophys. Res. Space Physics, 119, 4767-4785, doi:10.1002/2013JA019685.

Received 2 DEC 2013

Accepted 9 MAY 2014

Accepted article online 13 MAY 2014

Published online 2 JUN 2014

\section{Multisatellite observations of an intensified equatorial ionization anomaly in relation to the northern Sumatra earthquake of March 2005}

\author{
K. Ryu' ${ }^{1}$, E. Lee ${ }^{2}$, J. S. Chae' ${ }^{1}$, M. Parrot ${ }^{3}$, and K.-I. Oyama ${ }^{4,5}$ \\ ${ }^{1}$ Satellite Technology Research Center, Korea Advanced Institute of Science and Technology, Daejeon, South Korea, \\ ${ }^{2}$ School of Space Research, Kyung Hee University, Yongin, South Korea, ${ }^{3}$ LPC2E/CNRS 3A, Avenue de la Recherche \\ Scientifique, Orléans, France, ${ }^{4}$ Center for Space Weather Study and Education, Kyushu University, Fukuoka, Japan, \\ ${ }^{5}$ Institute of Plasma and Space Science, NCKU, Tainan, Taiwan
}

\section{Introduction}

There have been many reports on seismo-ionospheric coupling before and after large earthquakes [Hayakawa et al., 2000; Ondoh, 2003; Pulinets and Boyarchuk, 2004]. In parallel, theoretical studies were conducted [Namgaladze et al., 2009; Kuo et al., 2011] to explain the underlying mechanisms of the phenomena. Recently, statistical analyses using large sets of observational data obtained by ground facilities and satellites [Fujiwara et al., 2004; Liu et al., 2006; Li and Parrot, 2013] provided strong evidence that correlations between earthquakes and ionospheric anomalies actually exist. Meanwhile, case study approaches [Oyama et al., 2008, 2011; Ruzhin et al., 1998] were more insightful and efficient in understanding the underlying physics of the complicated lithosphere-ionosphere interactions.

Both in the observational [Oyama et al., 2008] and theoretical [Kuo et al., 2011] studies, it was stated that the electric field developed by the seismic activities at the lower boundary of the ionosphere triggered the seismo-ionospheric coupling, which is similar to the equatorial ionization anomaly (EIA). Since the EIA was discovered by Appleton [1954], it has been explained that the formation of the EIA is a result of the diurnal variation of the zonal electric field and its interaction with the horizontal geomagnetic field at the equatorial region, which uplifts the plasma by $\mathbf{E} \times \mathbf{B}$ drift [Anderson, 1981; Walker et al., 1994]. The variation of the EIA around the time of strong earthquakes was detected in the data of topside sounding from Intercosmos-19 satellite and reported by Pulinets et al. [2000]. Oyama et al. [2011] reported reductions of ion density in the DE-2 (the second Dynamics Explorer) satellite observations around a large earthquake that occurred in 1981. These changes in ion density showed characteristic latitudinal features similar to the EIA. In addition, Liu et al. [2011] reported ionospheric anomalies in the TEC (total electron content) values derived from GPS (Global Positioning System) signals which could be related to the 12 January 2010 M7 Haiti 
earthquake. These studies suggested a correlation between the seismo-ionosphere coupling process and the EIA variation in the equatorial region. In parallel, the tidal structure in the ionospheric plasma density at low latitudes has also been identified and studied [England et al., 2006; Immel et al., 2006; Liu and Watanabe, 2008]. The longitudinal wave structure in plasma density and the vertical plasma drift which determines the EIA features and variation in the equatorial ionosphere were explained in the contexts of geomagnetic field configuration [West and Heelis, 1996; Ren et al., 2009] and atmospheric tides [Sagawa et al., 2005; Immel et al., 2006].

In the last decade, concurrent operation of three satellites, Detection of Electro-Magnetic Emissions Transmitted from Earthquake Regions (DEMETER) [Parrot, 2002], CHAMP [Lühr et al., 2012], and DMSP (Defense Meteorological Satellite Program) [Coley et al., 2010], provided unprecedented opportunities to study ionospheric phenomena at various altitudes, simultaneously. In this study, we report multisatellite observations of the intensified EIA, which were thought to be caused by seismic activities related to the northern Sumatra earthquake of March 2005, using the apex height derived from the CHAMP satellite observations [Stolle et al., 2008] and the normalized equatorial plasma density derived from the DEMETER satellite observations. Based on these observations, the possible seismo-ionospheric coupling in the low-latitude region were investigated, leaving the need for ensuing studies to confirm and to assess the contribution of the seismic effects to the EIA variations. Assuming the observed features are caused by the seismic activity, we suggest a revised view of the seismo-ionospheric coupling, especially in the equatorial region, in accordance with the detailed geometry and the physical quantities of the underlying processes.

\section{Observations}

\subsection{Earthquake Occurrence}

The large earthquake of 28 March 2005 (M8.7; 2.065 $\mathrm{N}, 97.010^{\circ} \mathrm{E}$; Depth $=30 \mathrm{~km} ; 16: 09: 36$ UTC) occurred at the interface of the Australia and Sunda plates and was principally caused by the release of stresses that develop as the Australia plate subducts beneath the overriding Sunda Plate. The epicenter of the 28 March earthquake was located between the Nias and Simulue islands off the west coast of Sumatra, Indonesia. In the region of the earthquake, the Australia plate is known to move toward the northeast at a rate of about $5 \mathrm{~cm} / \mathrm{yr}$ relative to the Sunda plate. This results in oblique convergence at the Sunda Trench. The $28 \mathrm{March}$ earthquake was reported to have occurred as the result of thrust faulting. This earthquake was likely triggered by stress changes caused by the historic 26 December 2004 (M9.0) earthquake. However, the 28 March earthquake occurred on a segment of the fault $160 \mathrm{~km}$ to the southeast of the rupture zone of the M9.0 Sumatra earthquake. The 28 March earthquake is also known as the "Nias Earthquake" and records indicate that at least 1000 people were killed and 300 injured in Nias alone. A $3 \mathrm{~m}$ tsunami damaged the port and airport on Simulue. Tsunami heights of $2 \mathrm{~m}$ were observed on the west coast of Nias.

Large earthquakes (magnitude larger than 5.5) that occurred globally from a month before, to a month after, the northern Sumatra earthquake are listed in Table 1. The northern Sumatra earthquake is marked as EQ-29 in the chronological list of large earthquakes. During the period of interest, 31 of the 80 earthquakes that occurred worldwide, with magnitudes larger than 5.5, happened near the northeast coast of Sumatra along the Sunda Trench. The identification numbers of these earthquakes are underlined in the table. The underlined earthquakes along the Sunda Trench can be grouped into two clusters of earthquakes, one centered at $2^{\circ} \mathrm{N}, 97^{\circ} \mathrm{E}$ (Cluster 1 ) and the other at $1.7^{\circ} \mathrm{S}, 99.6^{\circ} \mathrm{E}$ (Cluster 2). The Cluster 1 earthquakes were mostly aftershocks of the main earthquake (EQ-29), which continued 10 days, while the Cluster 2 were due to the M6.7 earthquake (EQ-61) which occurred on 10 April, and its aftershocks.

If the observed ionospheric disturbances are caused by seismo-ionospheric coupling, the amplitude and size of the disturbance should be roughly proportional to the energy involved in the seismic activity. The relation between the magnitude of an earthquake ( $M_{s}$ Richter magnitude) and the total radiated seismic energy ( $E_{s}$ in joules) established by Gutenberg and Richter [1956] as $\log E_{s}=1.5 M_{s}+4.8$ implies that EQ-29 (at least, 10 times larger than any of the others) would be the dominant driver for any presumed ionospheric anomalies in this area and this period.

\subsection{Space Weather and Geomagnetic Activities}

Figure 1 shows the solar wind conditions and geomagnetic activities for 2 months (March to April) around the occurrence of the main earthquake. The solar wind conditions show that during this interval, solar wind speed and density recurrently increased and decreased (Figures 1e and 1f). Also, there were strong Alfvénic 
Table 1. List of Large Earthquakes That Occurred Around the Northern Sumatra Earthquake (29th in the List) ${ }^{\mathrm{a}}$

\begin{tabular}{|c|c|c|c|c|c|c|c|c|c|c|c|c|c|c|c|}
\hline$\#$ & M & D & UT & Latitude & Longitude & Depth & Magnitude & $\#$ & $M$ & D & UT & Latitude & Longitude & Depth & Magnitude \\
\hline 01 & 3 & 1 & $23: 57$ & -24.9 & -112.1 & 10 & 5.6 & 41 & 3 & 30 & $17: 41$ & -22.4 & -179.7 & 588 & 6.0 \\
\hline 02 & 3 & 2 & $10: 42$ & -6.5 & 129.9 & 201 & 7.1 & 42 & 3 & 31 & 01:39 & -18.5 & 176.0 & 10 & 5.9 \\
\hline 03 & 3 & 4 & 19:05 & 2.6 & 126.4 & 59 & 5.9 & 43 & 3 & 31 & $01: 46$ & -18.4 & 175.9 & 10 & 6.0 \\
\hline 04 & 3 & 5 & 19:06 & 24.6 & 121.9 & 3 & 5.7 & $\underline{44}$ & 3 & 31 & $07: 23$ & 1.7 & 97.1 & 22 & 5.8 \\
\hline 05 & 3 & 5 & 19:08 & 24.7 & 121.9 & 10 & 5.7 & 45 & 4 & 1 & $20: 32$ & 0.3 & 98.1 & 29 & 5.6 \\
\hline 06 & 3 & 6 & 01:39 & -11.0 & 163.2 & 10 & 5.9 & $\overline{46}$ & 4 & 2 & $12: 52$ & 78.6 & 6.0 & 10 & 6.1 \\
\hline 07 & 3 & 6 & 04:39 & -11.0 & 163.0 & 10 & 6.0 & $\underline{47}$ & 4 & 3 & $00: 59$ & 0.3 & 98.3 & 30 & 6.0 \\
\hline 08 & 3 & 6 & $05: 21$ & 84.9 & 99.3 & 10 & 6.3 & $\overline{48}$ & 4 & 3 & 01:41 & 13.5 & 120.8 & 129 & 5.6 \\
\hline 09 & 3 & 6 & $14: 59$ & -11.0 & 162.8 & 10 & 5.6 & 49 & 4 & 3 & 03:10 & 2.0 & 97.9 & 36 & 6.3 \\
\hline 10 & 3 & 7 & $07: 17$ & 11.3 & -85.9 & 85 & 5.6 & $\underline{50}$ & 4 & 4 & $04: 33$ & 1.6 & 97.8 & 30 & 5.6 \\
\hline 11 & 3 & 12 & $07: 36$ & 39.4 & 40.9 & 11 & 5.6 & $\overline{51}$ & 4 & 6 & $11: 20$ & -3.9 & 102.4 & 67 & 5.6 \\
\hline 12 & 3 & 13 & 03:31 & 27.0 & 61.8 & 54 & 6.0 & $\underline{52}$ & 4 & 7 & $11: 46$ & 0.6 & 97.4 & 26 & 5.6 \\
\hline 13 & 3 & 14 & 01:55 & 39.3 & 40.8 & 5 & 5.8 & 53 & 4 & 7 & $19: 43$ & 2.9 & 126.4 & 59 & 5.9 \\
\hline 14 & 3 & 14 & $05: 11$ & -27.7 & 73.8 & 10 & 5.6 & 54 & 4 & 7 & $20: 04$ & 30.4 & 83.6 & 11 & 6.3 \\
\hline 15 & 3 & 15 & $00: 15$ & 11.2 & -86.0 & 30 & 5.8 & $\underline{55}$ & 4 & 8 & $01: 51$ & 0.6 & 97.3 & 30 & 5.7 \\
\hline 16 & 3 & 16 & $22: 41$ & -52.3 & 159.5 & 10 & 5.6 & $\overline{56}$ & 4 & 8 & $05: 48$ & -0.2 & 97.7 & 20 & 6.1 \\
\hline 17 & 3 & 17 & $13: 37$ & 15.1 & -91.3 & 197 & 6.0 & $\overline{57}$ & 4 & 8 & $11: 38$ & -23.1 & 169.2 & 10 & 6.1 \\
\hline 18 & 3 & 17 & $23: 20$ & 4.8 & 95.0 & 60 & 5.7 & 58 & 4 & 9 & 02:08 & -47.2 & 100.3 & 10 & 5.8 \\
\hline$\overline{19}$ & 3 & 19 & $15: 02$ & -20.4 & -174.3 & 18 & 6.0 & 59 & 4 & 9 & $15: 16$ & 56.1 & -154.5 & 14 & 6.0 \\
\hline 20 & 3 & 19 & $17: 34$ & -21.8 & -179.5 & 598 & 6.3 & 60 & 4 & 9 & $15: 53$ & -53.4 & 25.3 & 10 & 5.7 \\
\hline 21 & 3 & 20 & $01: 53$ & 33.8 & 130.1 & 10 & 6.6 & $\underline{61}$ & 4 & 10 & $10: 29$ & -1.6 & 99.6 & 19 & 6.7 \\
\hline 22 & 3 & 20 & $17: 15$ & -7.9 & 124.8 & 28 & 5.8 & $\overline{62}$ & 4 & 10 & $10: 45$ & -1.6 & 99.6 & 30 & 5.7 \\
\hline 23 & 3 & 21 & $12: 23$ & -24.9 & -63.4 & 579 & 6.9 & $\overline{63}$ & 4 & 10 & $11: 14$ & -1.7 & 99.7 & 30 & 6.5 \\
\hline 24 & 3 & 21 & $12: 43$ & -24.7 & -63.5 & 570 & 6.4 & $\underline{64}$ & 4 & 10 & $11: 55$ & -1.7 & 99.7 & 29 & 5.8 \\
\hline 25 & 3 & 23 & $13: 59$ & -55.4 & -1.5 & 10 & 5.8 & $\overline{65}$ & 4 & 10 & $13: 39$ & -1.6 & 99.6 & 23 & 5.6 \\
\hline 26 & 3 & 23 & $21: 44$ & 39.4 & 40.9 & 10 & 5.6 & $\underline{\underline{66}}$ & 4 & 10 & $17: 24$ & -1.5 & 99.7 & 30 & 6.4 \\
\hline 27 & 3 & 25 & 01:04 & 5.4 & 94.3 & 39 & 5.8 & $\overline{67}$ & 4 & 10 & $22: 22$ & 35.5 & 140.3 & 43 & 5.9 \\
\hline$\overline{28}$ & 3 & 26 & $15: 40$ & -4.8 & 129.9 & 10 & 6.1 & $\underline{68}$ & 4 & 11 & $06: 11$ & 2.1 & 96.7 & 24 & 6.1 \\
\hline 29 & 3 & 28 & $16: 09$ & 2.0 & 97.1 & 30 & 8.7 & 69 & 4 & 11 & $12: 20$ & -3.4 & 145.9 & 11 & 6.6 \\
\hline$\overline{30}$ & 3 & 28 & $16: 21$ & 1.1 & 97.0 & 30 & 5.8 & 70 & 4 & 11 & $14: 54$ & -7.2 & -77.8 & 129 & 6.0 \\
\hline$\overline{31}$ & 3 & 28 & $16: 38$ & 1.2 & 97.4 & 30 & 5.9 & 71 & 4 & 11 & $17: 08$ & -21.9 & 170.6 & 68 & 6.7 \\
\hline$\underline{32}$ & 3 & 28 & $18: 30$ & 0.9 & 97.8 & 36 & 6.1 & $\underline{72}$ & 4 & 14 & $11: 29$ & -1.9 & 99.9 & 33 & 5.7 \\
\hline$\overline{33}$ & 3 & 28 & 19:02 & 1.0 & 97.8 & 30 & 5.8 & $\overline{73}$ & 4 & 14 & $22: 09$ & -22.2 & 171.4 & 123 & 5.6 \\
\hline$\overline{34}$ & 3 & 28 & $23: 13$ & 0.1 & 97.0 & 38 & 5.7 & 74 & 4 & 16 & $12: 18$ & -54.9 & -132.1 & 10 & 5.9 \\
\hline$\overline{35}$ & 3 & 28 & $23: 37$ & 2.8 & 96.4 & 29 & 5.6 & $\underline{75}$ & 4 & 16 & $16: 38$ & 1.8 & 97.6 & 31 & 6.4 \\
\hline$\overline{36}$ & 3 & 29 & 05:16 & 2.6 & 96.5 & 30 & 5.9 & $\overline{76}$ & 4 & 16 & $22: 41$ & -17.6 & -69.6 & 118 & 5.8 \\
\hline 37 & 3 & 30 & $01: 13$ & 1.7 & 97.0 & 27 & 5.7 & 77 & 4 & 19 & $01: 46$ & 29.6 & 138.8 & 425 & 5.9 \\
\hline 38 & 3 & 30 & $12: 00$ & -10.2 & 161.3 & 79 & 5.7 & 78 & 4 & 21 & $09: 26$ & 51.3 & -178.4 & 45 & 5.9 \\
\hline 39 & 3 & 30 & $16: 19$ & 2.9 & 95.4 & 22 & 6.3 & 79 & 4 & 25 & 02:32 & -27.0 & -176.5 & 32 & 5.6 \\
\hline$\underline{40}$ & 3 & 30 & $17: 29$ & 2.9 & 95.4 & 25 & 5.7 & $\underline{80}$ & 4 & 25 & $20: 18$ & 0.3 & 97.2 & 35 & 5.6 \\
\hline
\end{tabular}

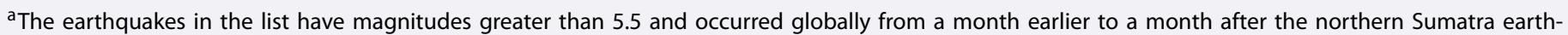
quake. Underlined earthquake numbers represent the earthquakes which are spatially related to the northern Sumatra earthquake.

fluctuations in the interplanetary magnetic field (IMF) when the solar wind speed was high (Figure 1d). For the solar wind and IMF, we used the OMNI data, time-shifted to the Earth's bow shock nose from the location of the ACE spacecraft; for details, refer to the website http://omniweb.gsfc.nasa.gov). These are the features of the corotating interaction regions. The geomagnetic activities caused by the high-speed solar wind streams with the strong Alfvénic fluctuations in the IMF are characterized by the continuous enhancement of the $K p$ or $A E$ index, which is often referred to as high-intensity, long-duration, continuous $A E$ activity [Tsurutani and Gonzalez, 1987]. Strong impacts of the high-speed solar wind streams on Earth's magnetosphere occurred on 5 March, about 23 days prior to the main earthquake, and on 4 April, about 7 days after the main earthquake. These resulted in moderate magnetic storms ( $\left.-50 \mathrm{nT}>D s t_{\min }>-100 \mathrm{nT}\right)$ and increases of the $K p$ greater than 4 . Another impact occurred about 3 days prior to the main earthquake, but it produced moderate disturbances only in the $K p$ index.

The response of the ionosphere to the high-speed solar wind streams is not clearly understood yet. Recently, Pedatella and Forbes [2011] reported using the DMSP F13 observations during 2005 that strong drift perturbations can occur in response to the high-speed streams. During the high-speed streams, the IMF 


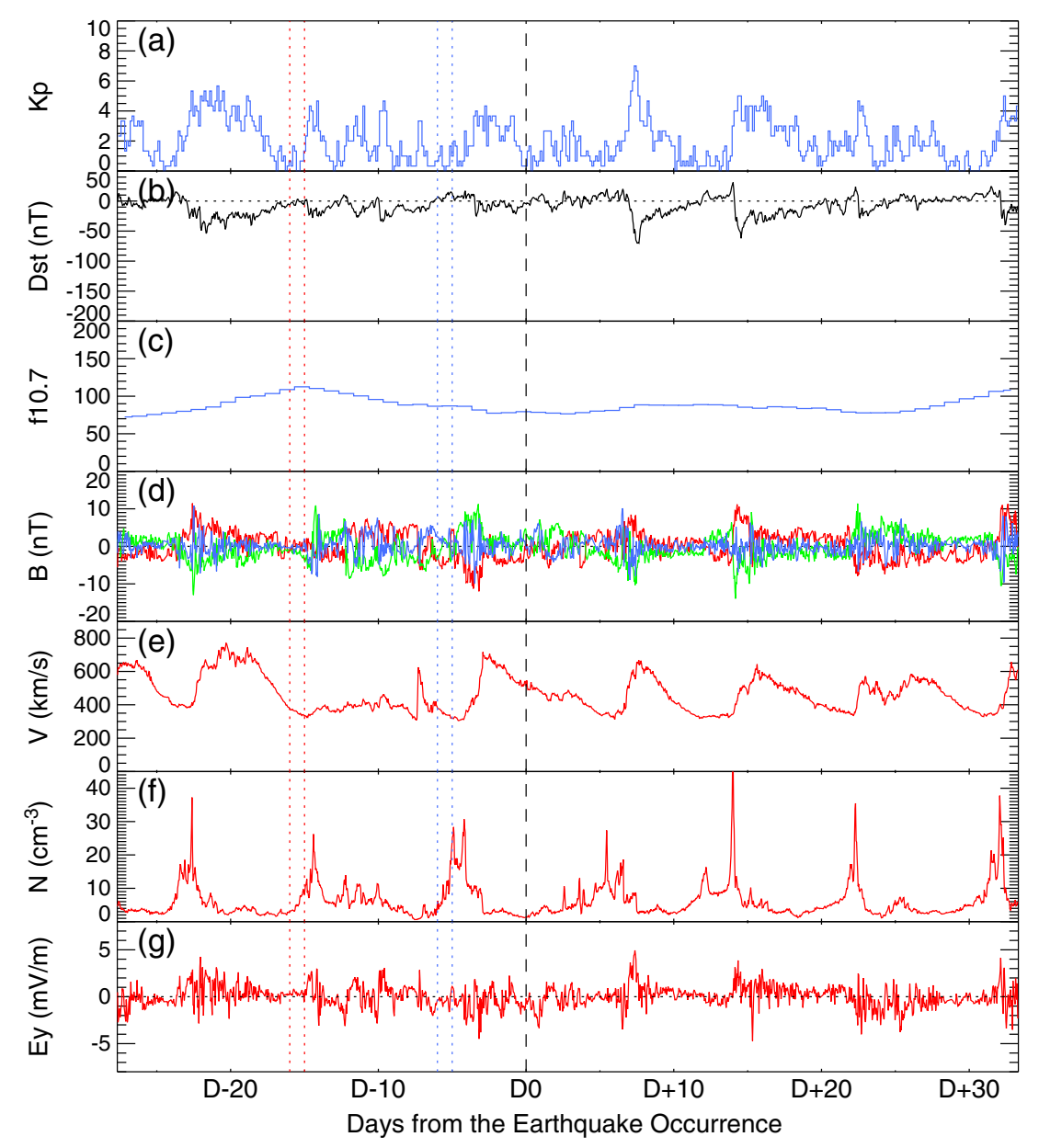

Figure 1. Geomagnetic and solar indices, and solar wind conditions, around the main earthquake on 28 March 2005: (a) $K p$ index, (b) Dst index, (c) $F_{10.7}$ solar radio flux, (d) interplanetary magnetic field ( $B_{x}$ : red, $B_{y}$ : green, and $B_{z}$ : blue), (e) solar wind speed, (f) solar wind density, and $(g)$ interplanetary electric field $\left(E_{y}\right)$. The vertical dashed line indicates the occurrence of the main earthquake. The red and blue vertical dotted lines indicate 15-16 days and 5-6 days prior to the earthquake, respectively.

shows Alfvénic fluctuations, which results in fluctuations in the interplanetary electric field (Figure 1g). The $E_{y}$ component of the interplanetary electric field is calculated as $\mathbf{E}_{y}=-\mathbf{V}_{x} \times \mathbf{B}_{z}$ and obtained from the OMNI data. The fluctuations in the $\mathbf{E}_{y}$ component of the interplanetary electric field could result in equatorial electric field and produce drift perturbations in the ionosphere [Manoj et al., 2008]. The main earthquake in this study occurred during the declining phase of a high-speed stream, the peak of which was about 3 days prior to the earthquake. Thus, the ionosphere could have been disturbed from 3 days prior to the earthquake (for 5-6 days). However, the disturbances would be weak as seen in the $K p$ and Dst indices. Also, the results from Pedatella and Forbes [2011] show that drift perturbations observed by DMSP F13 during this study period were not significant. Thus, it could be expected that the disturbances due to the solar wind conditions and geomagnetic activities would be weak. Moreover, to avoid any effects due to the solar wind conditions and geomagnetic activities, we will focus on the observations taken on 15-16 days and 5-6 days prior to the earthquake (marked as the vertical dotted lines in Figure 1), when the solar wind speeds were very low and Alfvénic fluctuations and the interplanetary electric field were weak.

The year 2005 was in the middle of the declining phase of Solar Cycle 23. Thus, the $F_{10.7}$ solar flux level was moderate and very slowly varying over the 60 day period, which suggests that the disturbances in the ionosphere directly caused by solar irradiance were insignificant. There existed slow enhancement of the $F_{10.7}$ flux about 2 weeks before the earthquake, but the variation was too slow to make any distinct disturbances. If the local time of satellite observation is maintained to within an hour or so, the ionospheric disturbances triggered by the $F_{10.7}$ flux changes would not obscure those triggered by seismic activities or other causes. 

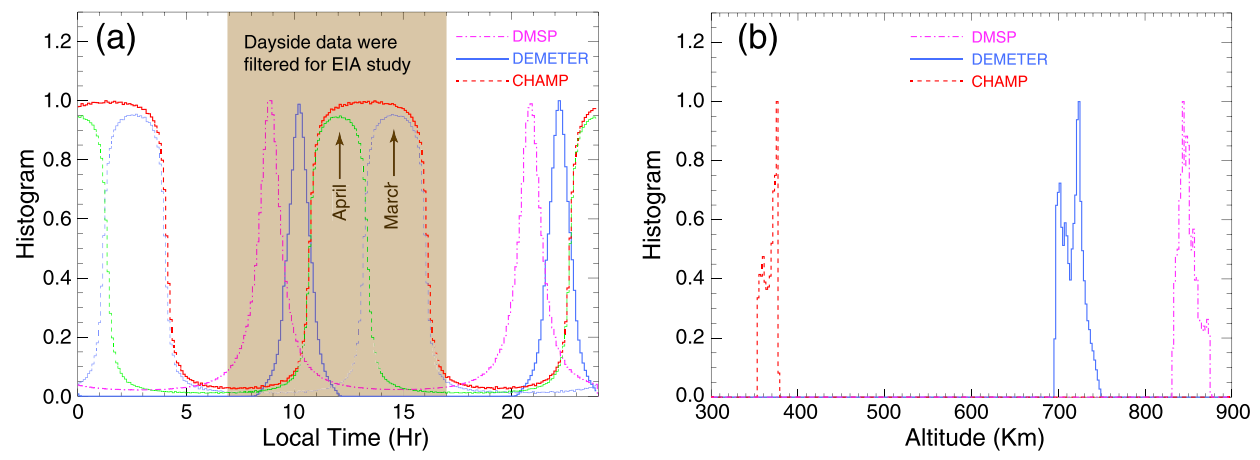

Figure 2. (a) Local time, and (b) altitude distribution, of three satellites during the study period (March and April of 2005). The pink dash-dotted lines, the blue solid lines, and the red dashed lines represent the cases of DMSP, DEMETER, and CHAMP satellites, respectively. The blue and green dashed lines in Figure 2a represent the local time distributions of CHAMP satellite measurements in March and April. The histogram values were normalized to " 1 " for each case. Only the daytime data, as marked by the dark brown box, were filtered for the analyses in this study.

In the case of the disturbances related to the seismo-ionospheric coupling process, the affected area would corotate with the Earth, and the disturbance would emerge if the longitudinal variations in the satellite measurements, at the same or similar local time, were investigated.

\subsection{Satellite Observations and Data Processing}

The DEMETER satellite was launched on 29 June 2004 [Cussac et al., 2006] for studying disturbances of the ionosphere caused by the seismo-electromagnetic effects. The DEMETER satellite measured the ionospheric plasma parameters and electromagnetic waves from a Sun-synchronous orbit at $710 \mathrm{~km}$ altitude, with local equatorial crossing on ascending node at 22:15. This makes it suitable for studying global ionospheric disturbances at fixed local times with varying geographic latitude and longitude. We utilized the measurement data from the retarding potential analyzer (Instrument d'Analyse du Plasma (IAP)) [Berthelier et al., 2006] and the Langmuir probe (Instrument Sonde de Langmuir (ISL)) [Lebreton et al., 2006]. The instruments measured in situ the electron density, electron temperature, ion density, and ion temperature. The German satellite CHAMP was launched in July 2000 into a circular, near-polar (inclination: $87^{\circ}$ ) orbit at $460 \mathrm{~km}$ altitude. During its lifetime, the orbit slowly decayed to $350 \mathrm{~km}$ altitude by the end of 2007, with final reentry into the atmosphere on 19 September 2010. The orbital plane precessed through local time at a rate of about 5.5 min per day, sweeping all time zones within 131 days. Among the various measurements, the electron density data collected by PLP (Planar Langmuir Probe) were utilized to compare with the other satellite measurements. The CHAMP electron density data were validated by McNamara et al. [2007]. For complementary analysis, the space environment sensors which have flown on DMSP F15 included in the SSIES (Special Sensors-lons, Electrons, and Scintillation) package (thermal plasma instruments including a retarding potential analyzer, lon Drift Meter, Langmuir probe, and scintillation meter) were also utilized. DMSP F15 was operational from 1999 and has a Sun-synchronous circular polar orbit at about $850 \mathrm{~km}$ altitude, with a nominal local time of ascending node at 21:12. The validity and ground data processing of DMSP F15 were described by Heelis [2006].

Figure 2 shows the distribution of the local times (Figure 2a) and altitudes (Figure 2b) of the three satellites when the measurements were made during the period from a month before and to a month after the earthquake occurrence. As shown in the histogram of local times, the ionospheric measurements by the DEMETER satellite were made at fixed local times centered around 10:15 LT (morning) and 22:15 LT (evening). As noted above, the local time of the CHAMP orbit slowly changes so that the local time distribution is wider than that of the DEMETER. The local times of the CHAMP orbit around the earthquake occurrence were centered on 15:00 LT in March and on 12:00 in April due to the orbit precession. The local time of the DMSP F15 satellite is fixed around 09:12 LT (morning). Though the local time of the three satellites did not coincide, the simultaneous observations by the satellites provide the opportunity to analyze features which continue more than several hours in local time, and have vertical structure. The altitude distributions of the satellites are shown in Figure 2b. The altitude distributions are centered around $360 \mathrm{~km}$ for CHAMP, $710 \mathrm{~km}$ for DEMETER, and $850 \mathrm{~km}$ for DMSP. As noted in the figure, the dayside data of the three satellites were used in the analysis of the EIA features. 


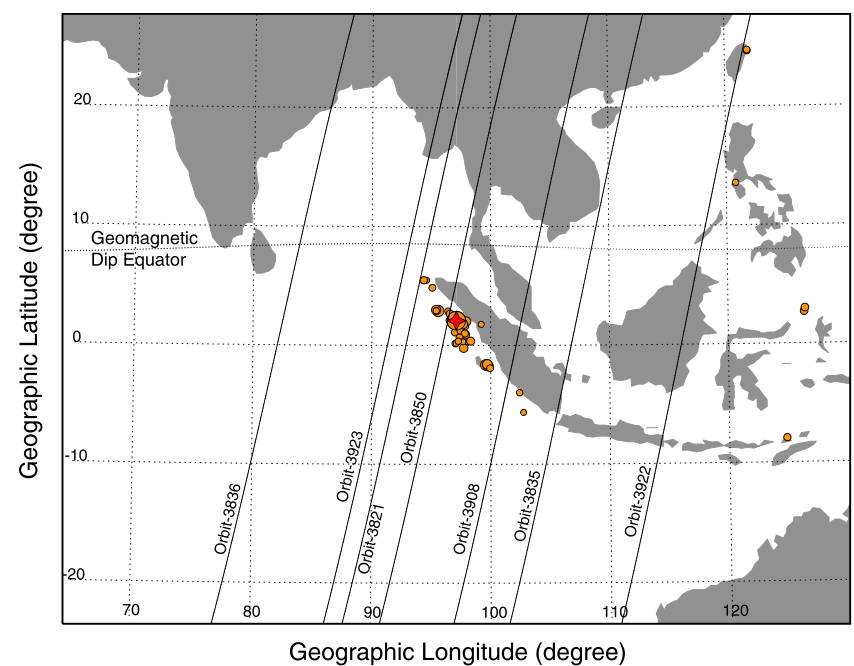

Figure 3. Geographic map framing the epicenter and the DEMETER satellite passes which were introduced explicitly in this study. The orbit numbers are shown on the trajectory. The epicenter of the main earthquake is marked with a red star symbol, while the epicenters of the large earthquakes that occurred during the study period (listed in Table 1) were represented as orange circles with diameters proportional to their earthquake magnitudes.

For this study, the ionospheric measurement data from 1 March to 30 April (1 month before and after the main earthquake on 28 March 2005) were collected and used in the analysis. The DEMETER ionospheric data were obtained via the Centre de Données de la Physique des Plasmas operated by le Centre National d'Etudes Spatiales and the CHAMP data via the Information System and Data Center operated by the Helmholtz Centre Potsdam. The DMSP data via the DMSP SSIES data distribution website were operated by the Center for Space Sciences at the University of Texas at Dallas.

\section{Results}

\subsection{Data Representation}

The data sets of three satellites during the period from a month before to a month after the northern Sumatra earthquake were processed to see if there exist precursory or ex-post ionospheric anomalies possibly related to the seismic activities, other than disturbances whose physical origins are known to be clearly different from seismic activities, such as the equatorial ionization anomaly and the storm-time ionospheric disturbance. It is practically impossible to show all the data or plots of them in limited pages, so that we will introduce some representative data subsets evenly distributed over the study period.

Figure 3 shows the geometry of the earthquake and satellite observations which will be referred to in the following figures. The directions of all the satellite passes are all southward during the study period. The DEMETER data are supplied with orbit counts assigned from the time of launch, while the others are not. The orbit numbers of the CHAMP and DMSP satellites were assigned in chronological order within the data set of the 2 month period and increase every half orbit of ascending and descending phase.

The ionospheric measurements around the northern Sumatra earthquake are shown in Figures 4-7. We realized that plotting the data within 2 day period is suitable for identifying abnormal behavior which deviates from slowly varying ionospheric changes. Four consecutive figures (starting from Figure 4) are the ionospheric parameters measured in the periods $D-16$ to $D-15$ (The designation "D-numeral" means the number of days before the main earthquake occurrence, while " $D+$ numeral" means the number of days after.), $D-6$ to $D-5$ (Figure 5), D0 to D+1 (Figure 6), and D+28 to D+29 (Figure 7). Each figure shows the measured values from four sensors consisting of the following: (a) the electron density measured by the DEMETER ISL, (b) the $\mathrm{O}^{+}$density by the DEMETER IAP, (c) the electron temperature by the CHAMP PLP, and (d) the vertical drift velocity by the DMSP SSEIS.

Every graph consists of two panels. In each graph, the panel at the top shows the data from all the satellite orbits during the 2 day period. Longitudinal distance is defined as the difference in the longitudes between the epicenter of the main earthquake and the position of the satellite when it passes the same latitude of 
(a)

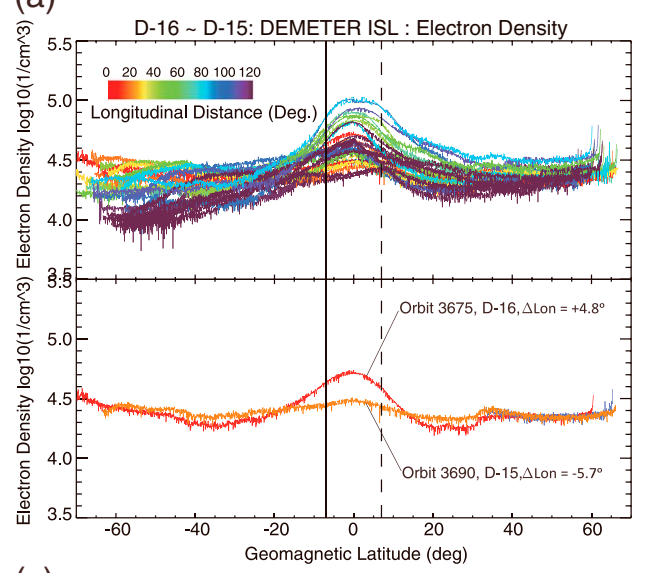

(c)

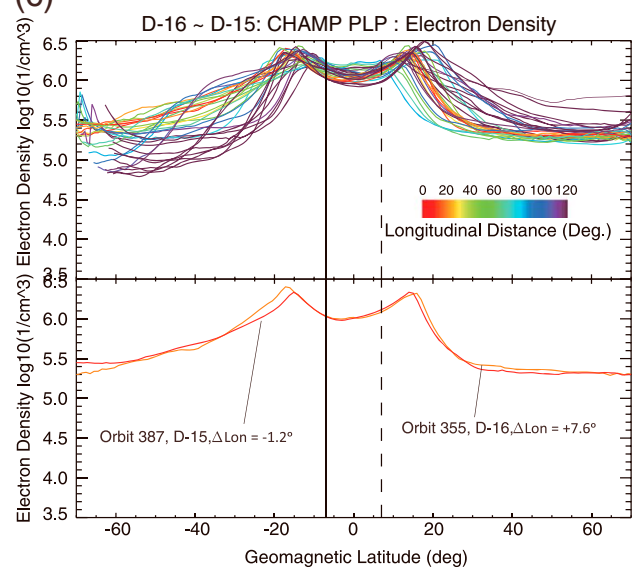

(b)

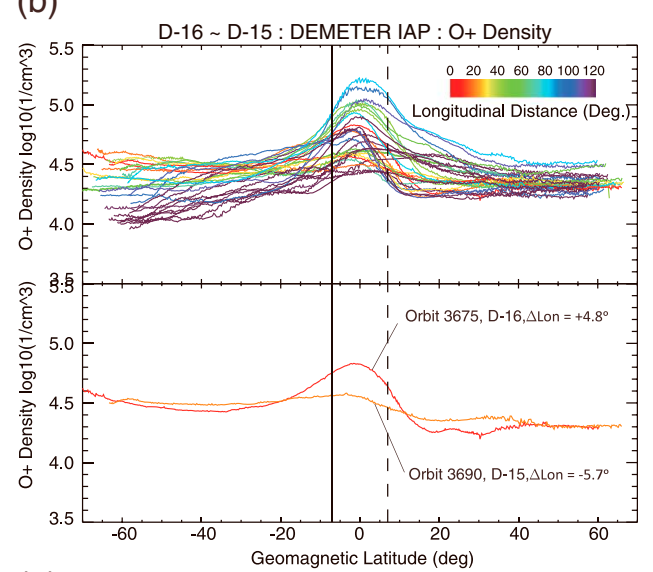

(d)

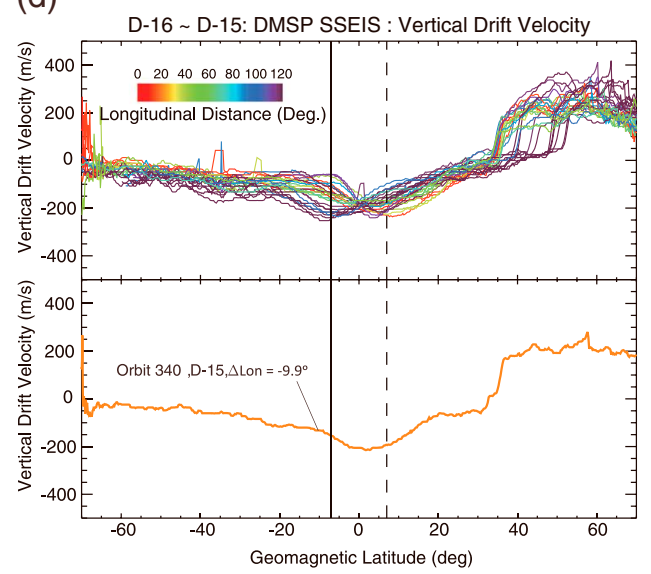

Figure 4. lonospheric conditions measured from D-16 to D-15 (12-13 February 2005). The graphs represent the latitudinal profiles of the following: (a) the electron density measured by the DEMETER ISL, (b) the $\mathrm{O}^{+}$density measured by the DEMETER IAP, (c) the electron density measured by the CHAMP PLP, and (d) the vertical drift velocity measured by the DMSP SSEIS. Each consists of two panels. The panels at the top show the entire profiles measured during the 2 day period. The longitudinal distances from the main earthquake location were represented as varying colors (see color bars). The panels at the bottom show the measured data profiles with longitude less than $10^{\circ}$ from the epicenter.

the epicenter. Longitudinal distances from $0^{\circ}$ to $120^{\circ}$ are represented by colors (see the color bar) shown together in the panel at the top. Saturated dark blue represents data over longitudinal distances larger than $120^{\circ}$. All the measured values were plotted as a function of the geomagnetic latitude according to a recent suggestion of Oyama et al. [2011] that a seismic ionization anomaly, in their case a reduction of the ion density, might be caused by the interaction of the electric field associated with earthquakes and geomagnetic field. The vertical solid and dashed lines in the graphs represent the geomagnetic latitude of the epicenter (solid line) and its conjugate latitude (dashed line), respectively. The panel at the bottom shows the data for those orbits whose longitudinal distance was less than $10^{\circ}$. The red line represents shorter distance, while the orange lines represent longer longitudinal distance.

\subsection{Ionospheric Conditions Before the Earthquake}

The ionospheric conditions about 2 weeks before the earthquake are shown in Figure 4. Throughout this study, we were careful to utilize only the relative variation in the DEMETER ISL data instead of the absolute values. In any case, the ISL (Langmuir probe) and the IAP (retarding potential analyzer), which measure the electron density and ion density, generally showed self-consistent values proportional to each other.

The ISL and IAP measurements of the electron and the ion $\left(\mathrm{O}^{+}\right)$density do not show crests-trough profiles. Instead, the plasma density values are higher around the equator region, with bulge-like profiles. The profiles of DEMETER measurements are asymmetric with respect to the geomagnetic equator. The electron and $\mathrm{O}^{+}$density in the Northern Hemisphere is higher than those of the Southern Hemisphere in general. 
(a)

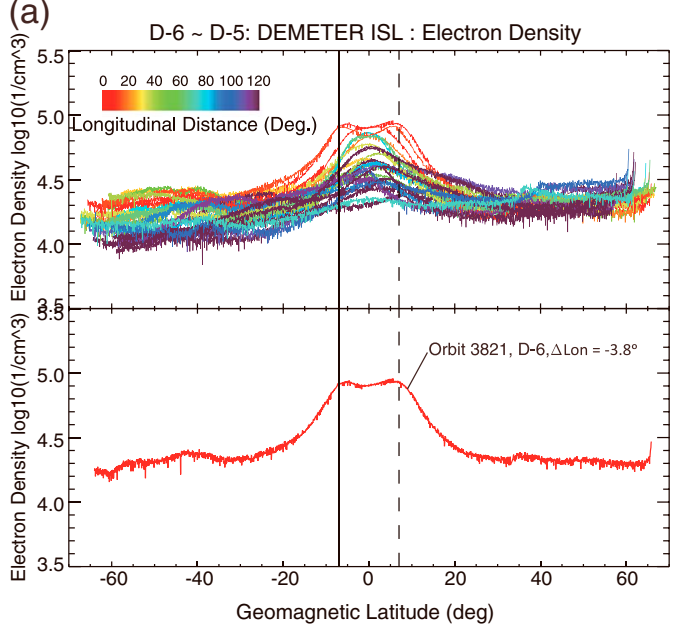

(c)

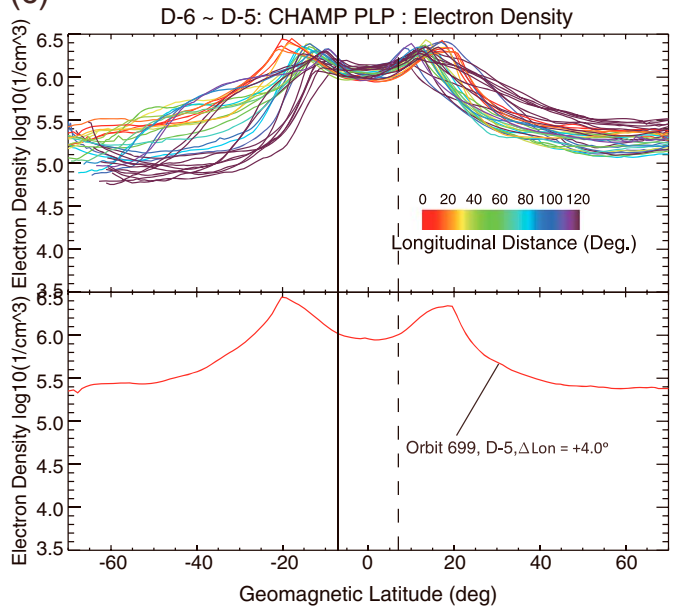

(b)

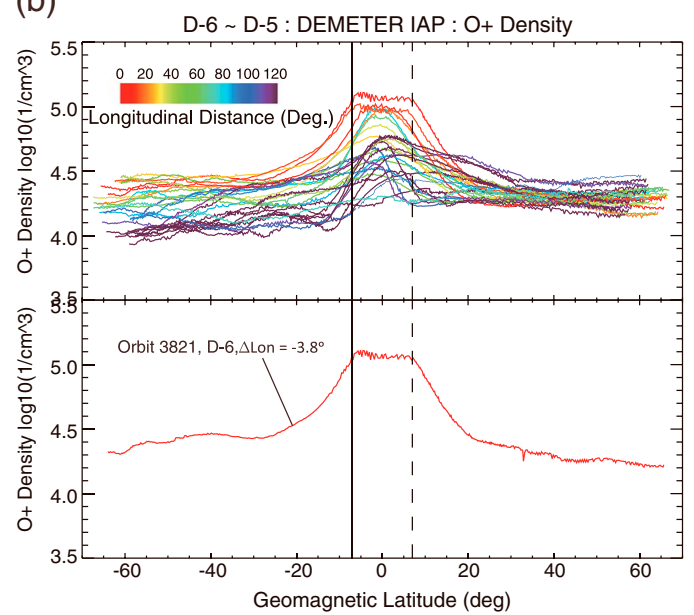

(d)

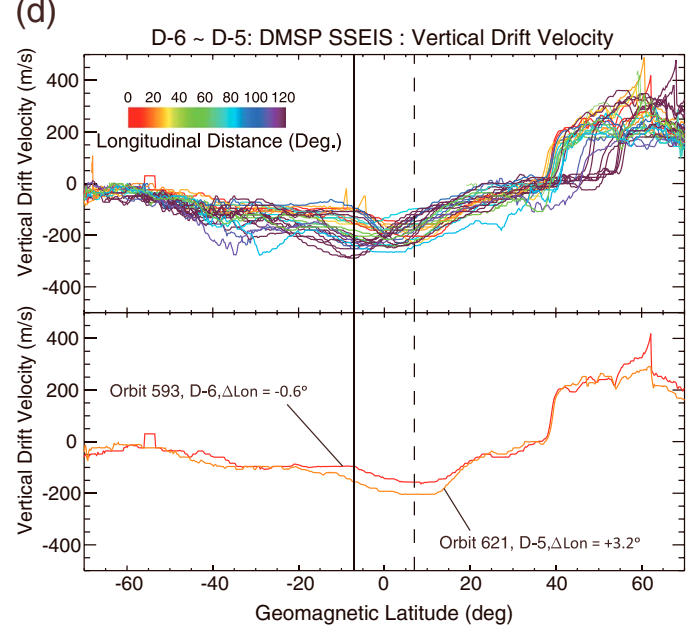

Figure 5. lonospheric conditions measured from D-6 to D-5 (22-23 February 2005). The content and method of representing the parameters are exactly the same as for Figure 4.

There appear longitudinal variations in the density profiles. Regarding the electron density (Figure 4), the ionospheric conditions along satellite orbits that passed over the epicenter region (e.g., Orbit-3675 (D-16) and Orbit-3690 (D-15)) do not show any peculiarity compared with other orbits. The electron density profile of these close orbits stay within the $1 \sigma$ range of the measurements, which were made in the 2 day period, throughout the latitude (Figure $4 a$ ). The $\mathrm{O}^{+}$(Figure $4 \mathrm{~b}$ ) density shows direct proportional correlation with electron density along each orbit. Both the electron and $\mathrm{O}^{+}$densities measured by the ISL and IAP, respectively, are similar to or larger than $1.0 \times 10^{5}$ particles $/ \mathrm{cm}^{3}$. Features typical of the equatorial ionization anomaly (EIA) are shown in the electron density profiles measured by the CHAMP PLP (Figure 4e).

To quantify the strength and morphology of the EIA, Mendillo et al. [2000] defined a strength index $\left(I_{S}\right)$ and an asymmetry index $\left(I_{a}\right)$ as follows:

$$
\begin{aligned}
& I_{s}=(N+S) / E \\
& I_{a}=(N-S) /((N+S) / 2),
\end{aligned}
$$

where $N, S$, and $E$ represent the TEC at the north and south crests, and at the equator trough, respectively. Later, Stolle et al. [2008] similarly defined the Crest-to-Trough Ratio (CTR), which is analogous to the strength index, by substituting the TEC with the electron density measured by the CHAMP PLP. In addition, they defined the crest $L$ value of the flux tube, $L_{c}=1 / 2 \cdot\left(L_{N}+L_{S}\right)$, where $L_{N}$ and $L_{S}$ are the $L$ values of the north and south crests, as a measure of the altitude-independent EIA width. The satellite passes at longitudinal distances less than $50^{\circ}$ (represented as red, yellow, and green lines) show asymmetric increase in 
(a)

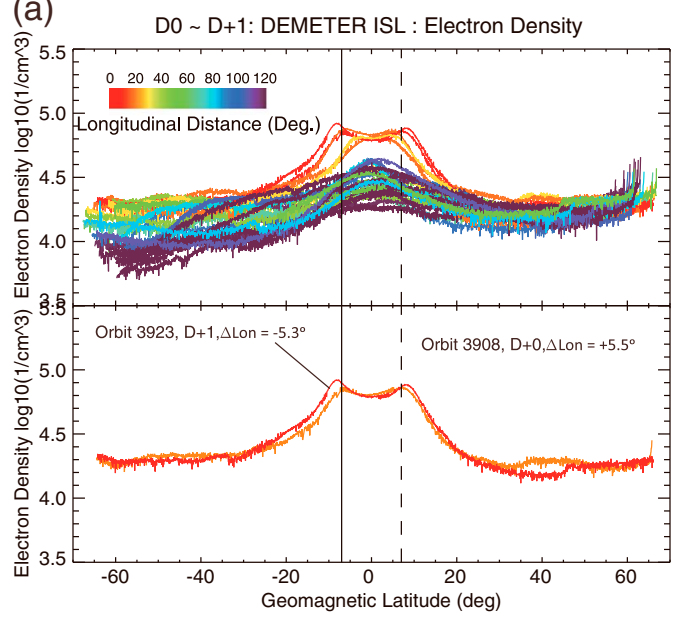

(c)

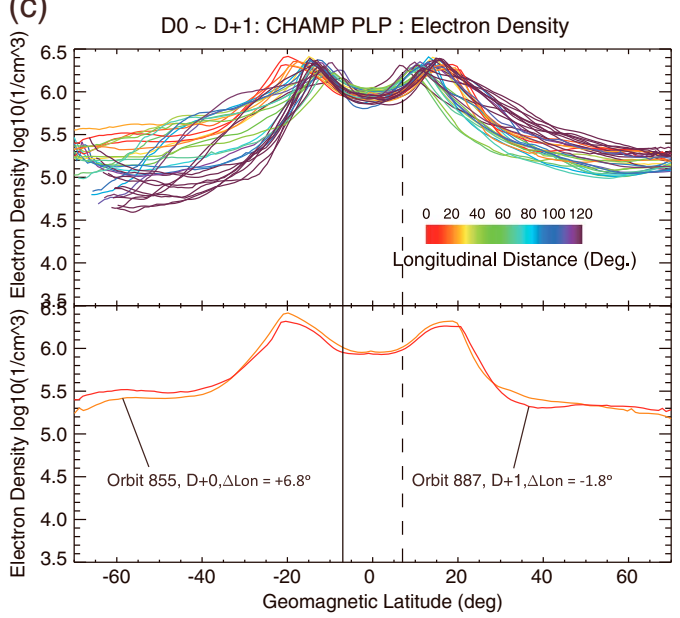

(b)

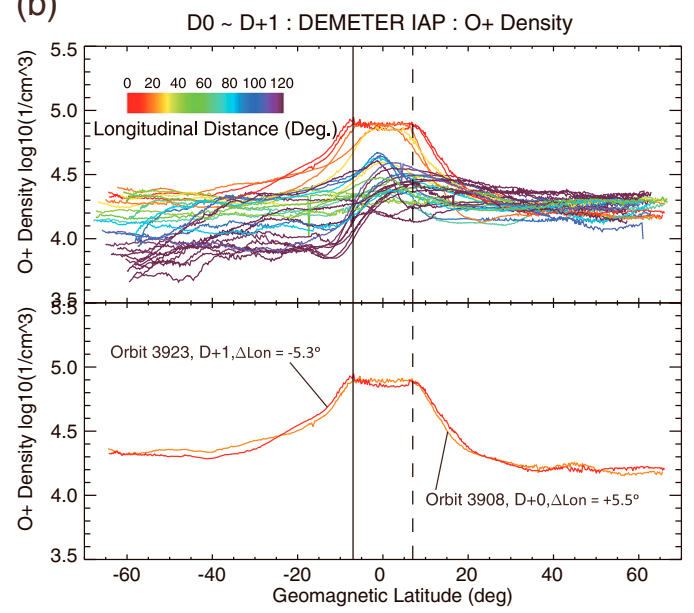

(d)

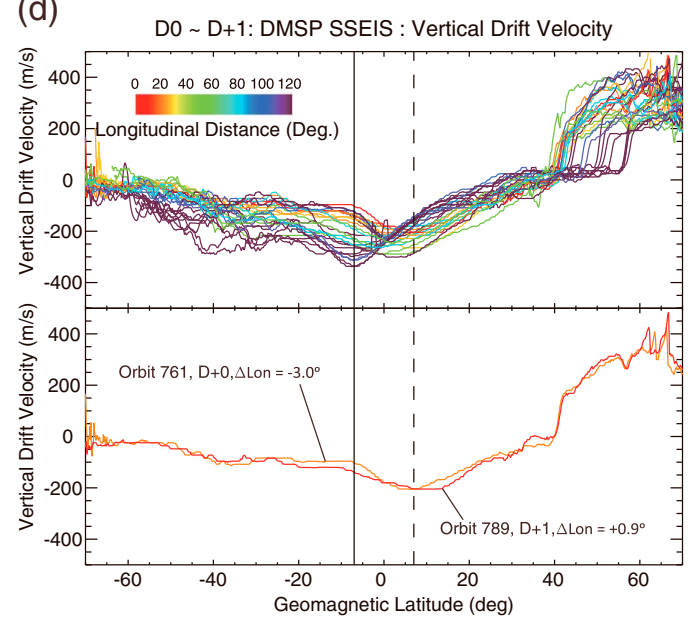

Figure 6. Ionospheric conditions measured from D0 to D+1 (28 February to 1 March 2005). The content and method of representing the parameters are exactly the same as for Figure 4.

the Southern Hemisphere when compared with other orbits. This feature also can be seen in the DEMETER electron and $\mathrm{O}^{+}$density profiles. We could not figure out whether this feature should be thought of as a seismo-ionospheric coupling, or just a short-term local phenomenon. The CTR along the orbit closest to the epicenter (Orbit-387 at $\mathrm{D}-15$ with $\Delta$ lon $=-1.2^{\circ}$ ) during the study period is estimated to be $\sim 2.5$. The crest $L$ value can be derived assuming that the geomagnetic field is given by the dipole geometry as follows:

$$
L_{c}=\frac{R_{E}+h_{\text {sat }}}{R_{E}} \frac{1}{\cos ^{2} \beta_{c}},
$$

where $R_{E}(6371 \mathrm{~km})$ is the radius of the Earth, $h_{\text {sat }}$ is the altitude of the satellite, and $\beta_{c}$ is the geomagnetic latitude of the crest. The $L_{c}$ for Orbit-387 was estimated to be 1.134 since the crests were located $\sim 15^{\circ}$ north and south of the geomagnetic equator. The vertical drift velocity profiles measured during the study period by the DMSP SSEIS are shown in Figure 4f. The vertical drift velocity around the geomagnetic equatorial region is roughly $-200 \mathrm{~m} / \mathrm{s}$ (downward direction) regardless of the longitude. It is thought that the DMSP altitude might be around the apex height where the EIA uplifted plasma starts to diffuse downward along the flux tube. We tried to make use of the relative changes of the velocity values throughout this study, considering the difficulties in measuring the ion drift velocity in the high-altitude region of the ionosphere where the density is very low.

\subsection{Precursory lonospheric Phenomena}

Figure 5 shows the ionospheric condition measured by the three satellites about a week ( $D-6$ to $D-5$ ) before the main shock. The electron and $\mathrm{O}^{+}$densities were much higher when the DEMETER satellite passed near the epicenter (Figures $5 a$ and $5 b$ ). This is commonly seen in the orbits with longitudinal distance less 
(a)

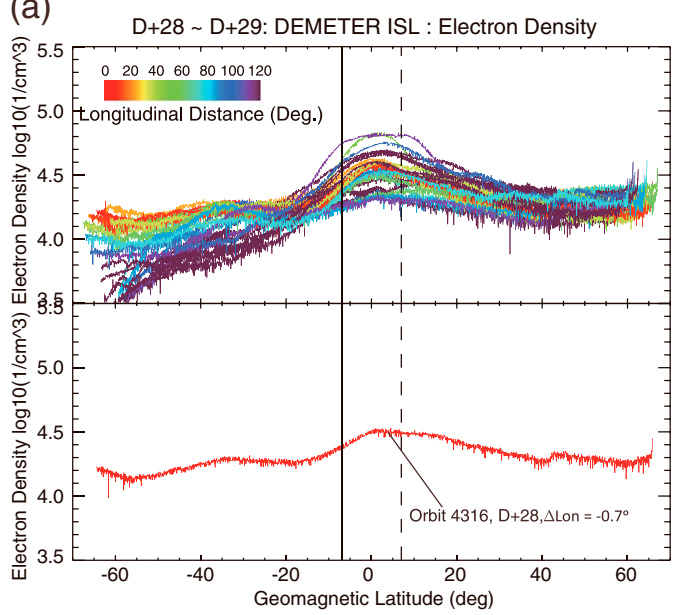

(c)

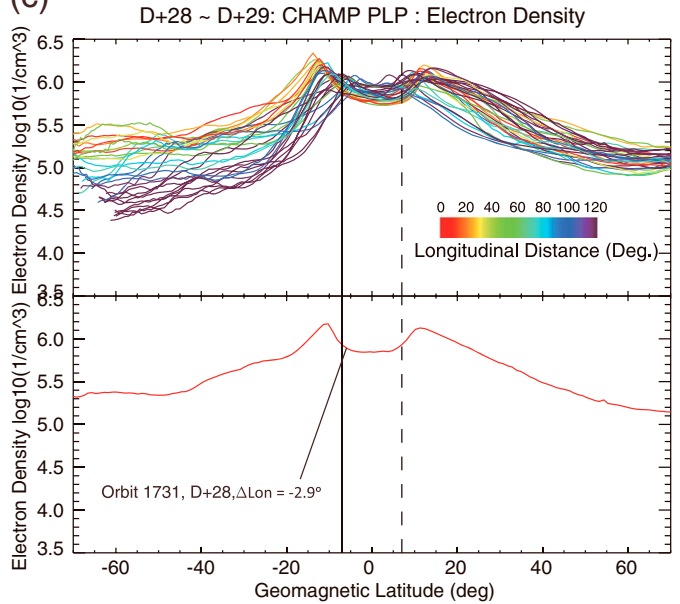

(b)

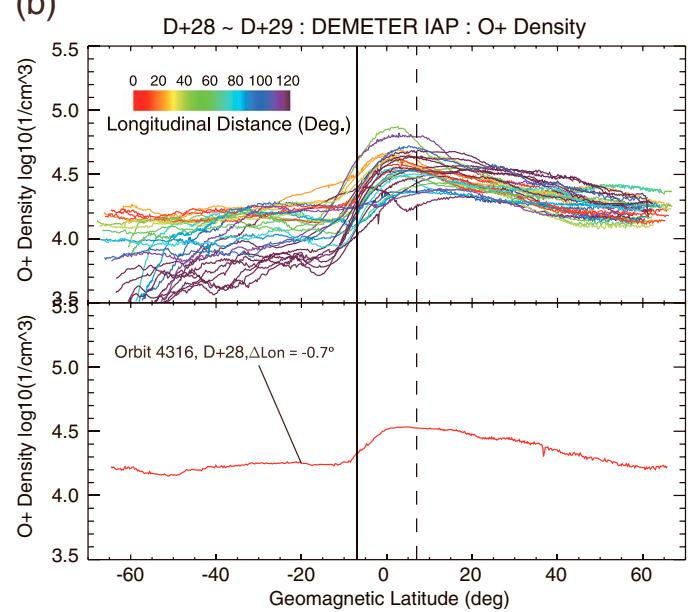

(d) D+28 D+29: DMSP SSEIS : Vertical Drift Velocity

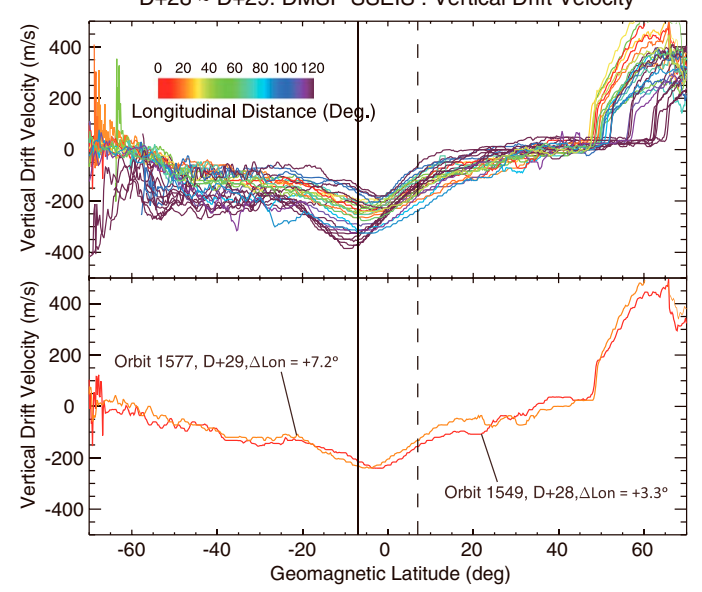

Figure 7. Ionospheric conditions measured from D+28 to D+29 (28-29 March 2005). The content and method of representing the parameters are exactly the same as for Figure 4.

than $20^{\circ}$ (red on the graphs). It appears that the feature reached its climax in the closest orbit (Orbit-3812, at $D-6$, with longitudinal distance $-3.8^{\circ}$ ). There exist crests in the electron density profiles of the two orbits closer to the epicenter than any other orbits. The geomagnetic latitudes of the crests coincide with the latitude of the epicenter and its geomagnetic conjugate.

As can be found in Figure 5 a (bottom), there existed a small trough in the electron density profile, but $N_{e}$ at the trough did not show a large difference from those at the crests. If the crests and trough morphology are expressed in CTR as for CHAMP, the CTR derived from $N_{e}$, measured at the altitude of DEMETER, would be $\sim 1.2$ in Orbit-3821. The crest $L$ value was estimated to be 1.130. In the case of $\mathrm{O}^{+}$density (Figure $5 b$ ), Orbit-3821 does not have a trough in this profile. Instead, the $\mathrm{O}^{+}$density profile looks as if it is saturated to a fixed value of $\sim 1.0 \times 10^{5}$ particles $/ \mathrm{cm}^{3}$ within the region encompassed by the epicenter latitude and its geomagnetic conjugate.

The electron density profiles measured by the CHAMP PLP (Figure 5c) look as if they are merely typical features of the equatorial ionization anomaly. A thorough investigation revealed that the profiles of the orbits whose longitudinal distances were less than $30^{\circ}$ had larger crest $L$ values than did those of the farther orbits. The closest orbit (Orbit-699 at $D-5$ with $\Delta$ lon $=+4.0^{\circ}$ ) had the largest $L_{c}$-reaching $1.20\left(\beta_{c}=20^{\circ}\right)$ in both direction from the equator. This corresponded to $\sim 1250 \mathrm{~km}$ altitude at the equator along the geomagnetic flux tube.

In the case of the vertical drift velocity measured by the DMSP satellite, the epicenter-close orbits (Orbit-593 and Orbit-621) have slightly higher values around the epicenter, though the overall drift direction is 
downward. If we only consider the meaning of the relative change of the drift velocity measurements (as described in section 3.2), we carefully state that there could exist a reinforcement in the vertical uplift which causes the usual EIA in the vicinity of the epicenter.

\subsection{Concurrent and Ex-Post lonospheric Conditions}

The ionospheric conditions on the day of the earthquake occurrence, and on the day after the occurrence, are shown in Figure 6. Essentially the same phenomena described in Figure 5 were still maintained. The electron density measured by DEMETER had crests with slightly larger $L_{c}$-compared with that of the period D-6 to D-5. The CHAMP PLP data also show ElA with increased $L_{c}\left(\beta_{c} \approx 22^{\circ}\right.$ both in the south and north), suggesting that there exists a more intensified vertical uplift along the geomagnetic flux tube which passes the longitude of the epicenter.

Orbit-3908 of the DEMETER satellite (Figures 6a and 6b) passed the equator on the dayside (descending) at $3 \mathrm{~h} 24 \mathrm{~m}$ UTC on 28 March. If the intensified EIA feature was seismo-ionospheric coupling, the ionospheric feature along the epicenter longitude appearing in Orbit-3908 can be considered a precursory phenomenon since it preceded the earthquake at $16 \mathrm{~h} 09 \mathrm{~m}$ UTC (see Table 1). It appears that there were no specific differences in the precursory, the concurrent, and the ex-post seismo-ionospheric coupling except in the intensity or the magnitude of the disturbances.

The atypical pattern in the electron and $\mathrm{O}^{+}$density appeared from a week before the earthquake (as shown in Figure 5) and continued until about a week after the main shock. Then the ionospheric condition returned to a state similar to that before the precursory disturbances were observed. Figure 7 shows the ionospheric parameters observed a month ( $D+28$ to $D+29)$ after the main shock. The electron density measured by the DEMETER ISL around the epicenter longitude and latitude remained within $1 \sigma$ deviation range of statistical ensemble shown in Figure 7a. The $\mathrm{O}^{+}$density was similar. The EIA feature appeared, regardless of the longitudinal variation, but the $L_{c}$ was reduced to $\sim 1.11$, which is even slightly smaller than that for Orbit-387 on D-15.

\subsection{Change of the EIA-Related Parameters}

The crest $L$ value were derived from the CHAMP PLP electron density measurement during the 2 month period before and after the northern Sumatra earthquake. The crest $L$ value can be directly converted to the apex height, $H_{\text {apex }}$ using the geomagnetic dipole approximation $H_{\text {apex }}=R_{E}\left(L_{c}-1\right)$. The apex height has clearer physical insight than the crest $L$ value since $H_{\text {apex }}$ in kilometer is the altitude of the flux tube at the geomagnetic equator containing the EIA crests.

Figure 8a shows the change of the apex height derived from the CHAMP PLP measurements during the 2 month study period. An apex height value was assigned to a daytime orbital pass so that each point on the graph represents the apex height at longitude of the satellite orbit when it passes the equator on the dayside. The $x$ axis on the graph refers to the time in days with respect to the time of the main earthquake (the vertical dashed line at $x=0$ ). As shown on the graph, the apex height values for all the orbits in the study period are marked as color-filled circles whose colors and sizes vary according to the apex height values. The $y$ axis represents the longitude at which the satellite passes the geographic equator while descending on the dayside. The horizontal dashed line represents the geographic longitude of the epicenter. The CTR values derived from the CHAMP PLP were plotted in Figure 8b. Since the local time of the CHAMP satellite varied, the values were normalized to the values at noon. The variations of the $H_{\text {apex }}$ and CTR values as a function of local time, in the same season (March and April), were derived from the CHAMP observation period except 2005 and were fit to polynomial functions.

Increases in apex heights derived from the EIA crests can clearly be seen in the orbits close to the epicenter longitude $\left(97.1^{\circ}\right)$ about 2 weeks before and after the earthquake. The clusters of these orbits with large apex heights are distributed within $\sim 20^{\circ}$ in longitudinal distance from the epicenter. Even though not all the orbits in the range $\left(D-14<T<D+14, \Delta\right.$ long $\left.<20^{\circ}\right)$ had relatively large $H_{\text {apex }}(>1000 \mathrm{~km})$, almost half of the orbits have apex heights larger than $1000 \mathrm{~km}$, clearly distinct from other orbits. There appeared some orbits with the EIA apex heights greater than $1000 \mathrm{~km}$, but they were not clustered in temporal or spatial vicinity. The CTR (Figure 8b) did not show clear correlation with $H_{\text {apex }}$, though the CTR was slightly enhanced along $\sim 90^{\circ} \mathrm{E}$ and $\sim 300^{\circ} \mathrm{E}$.

As shown in the previous section, there appeared EIA features in the DEMETER electron and ion density measurements temporally near the main earthquake. Unlike the CHAMP measurements, only some 
(a)

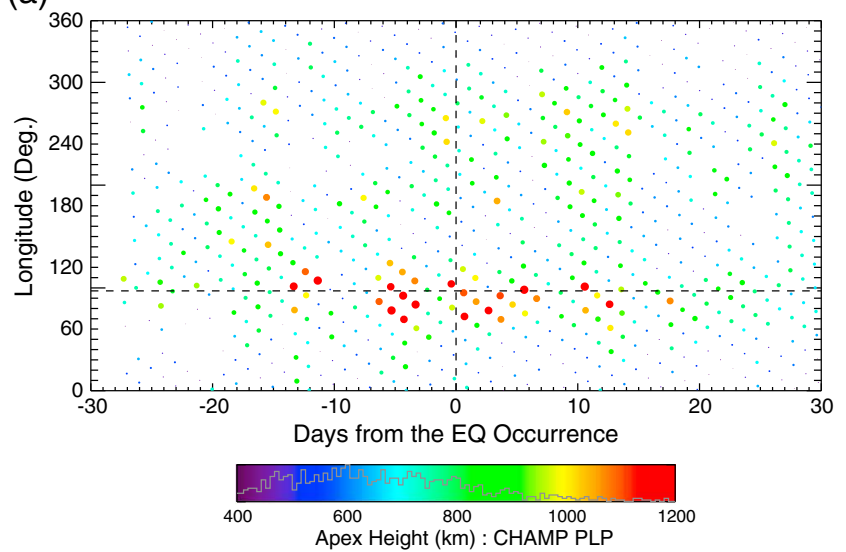

(b)

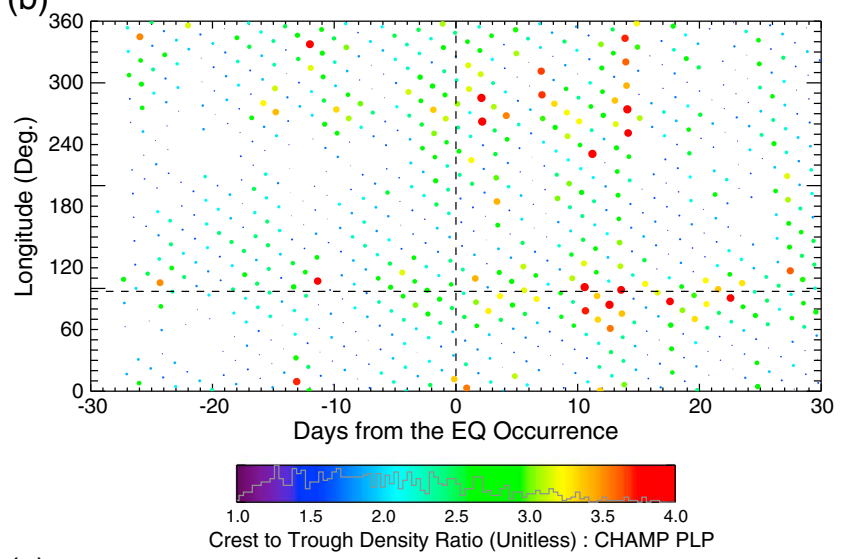

(c)

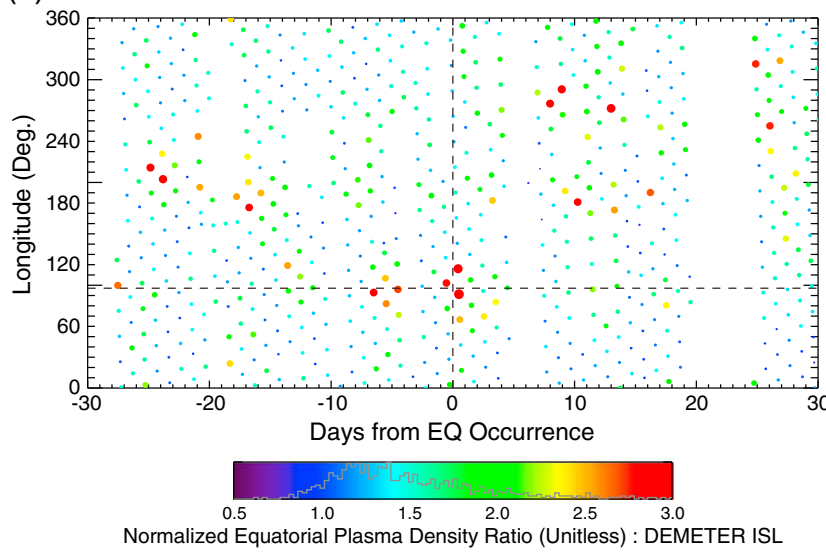

Figure 8. Distributions of (a) the apex height derived from the CHAMP PLP electron density profile, (b) the CTR derived from the PLP, and (c) the normalized equatorial plasma density derived from the DEMETER ISL, as defined in the text. The $x$ axis represents the time in days with respect to the main earthquake event, while the $y$ axis is the longitudes at which the satellites pass the geometric equator. The vertical dashed lines designate the time of the main earthquake and the horizontal dashed lines denote the geographic longitude of the epicenter $\left(97.1^{\circ} \mathrm{E}\right)$. The colors of the filled circles are assigned according to the parameters as defined by the color bars. The sizes of the filled circles are also proportional to the values. The histograms are shown within the color bars.

gitudinal variations of the NEPD measured by DEMETER were analyzed. First, the temporal evolution of the NEPD in the vicinity of the epicenter region during the study period (March and April of 2005) is shown in parts of the dayside orbits showed the EIA features. Thus, it is not possible to quantify the intensity of the anomaly using the crest $L$ value for all the orbits in the study period. Instead, we defined the normalized equatorial plasma density (NEPD, hereafter) analogous to the methodology of Kil et al. [2008]. While they normalized the equatorial plasma density by the longitudinal mean density, we normalized the equatorial electron density $\left(-15^{\circ}<\right.$ geomagnetic latitude $\left.<15^{\circ}\right)$ by the midlatitude $\left(30^{\circ} \mathrm{N}<\right.$ geomagnetic latitude $<50^{\circ} \mathrm{N}$ ). The electron density in the Southern Hemisphere have longitudinal dependence, so the reference density was derived by taking averages of the electron density values between $30^{\circ}$ and $50^{\circ}$ north in geomagnetic latitude.

Figure $8 c$ shows the change in the NEPD during the study period. The method of representing the data is the same as in Figure 8a except that the apex height values were substituted by the NEPD values. Most of the orbits have values less than 3.0 (represented in blue and green). There were 15 orbits with the NEPD greater than 3.0 (shown as red filled circles). Among them, six orbits were distributed within $\sim 20^{\circ}$ from the epicenter longitude and are five out of the six orbits were temporally clustered from a week before the earthquake to a day after the occurrence. For two orbits (Orbit 3908 and 3923 in Figure 6), right after the main shock, the NEPD values are even higher than 3.5. DEMETER Orbit 3923 which passed $5.3^{\circ}$ west of the epicenter on the day after the earthquake, had the normalized density value of 4.0 , the maximum value registered during the study period. It can be deduced that the more intense or increased uplift of the ionospheric plasma was related to those orbits that had relatively larger NEPD values.

To investigate the possible correlation of the intensified EIA features with the seismic activity, the temporal and lon(March and April of 2005) is shown in
and the temporal evolution of the 
(a)

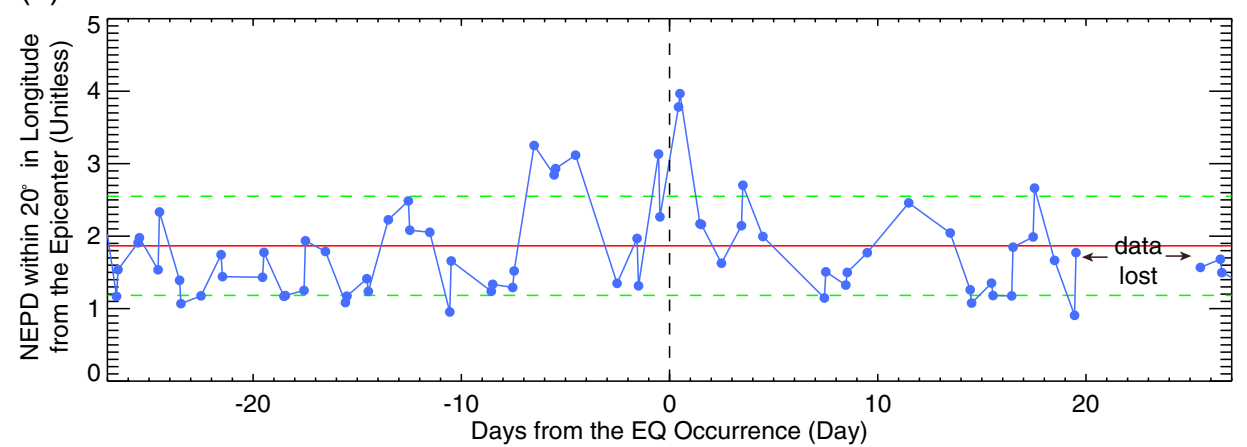

(b)

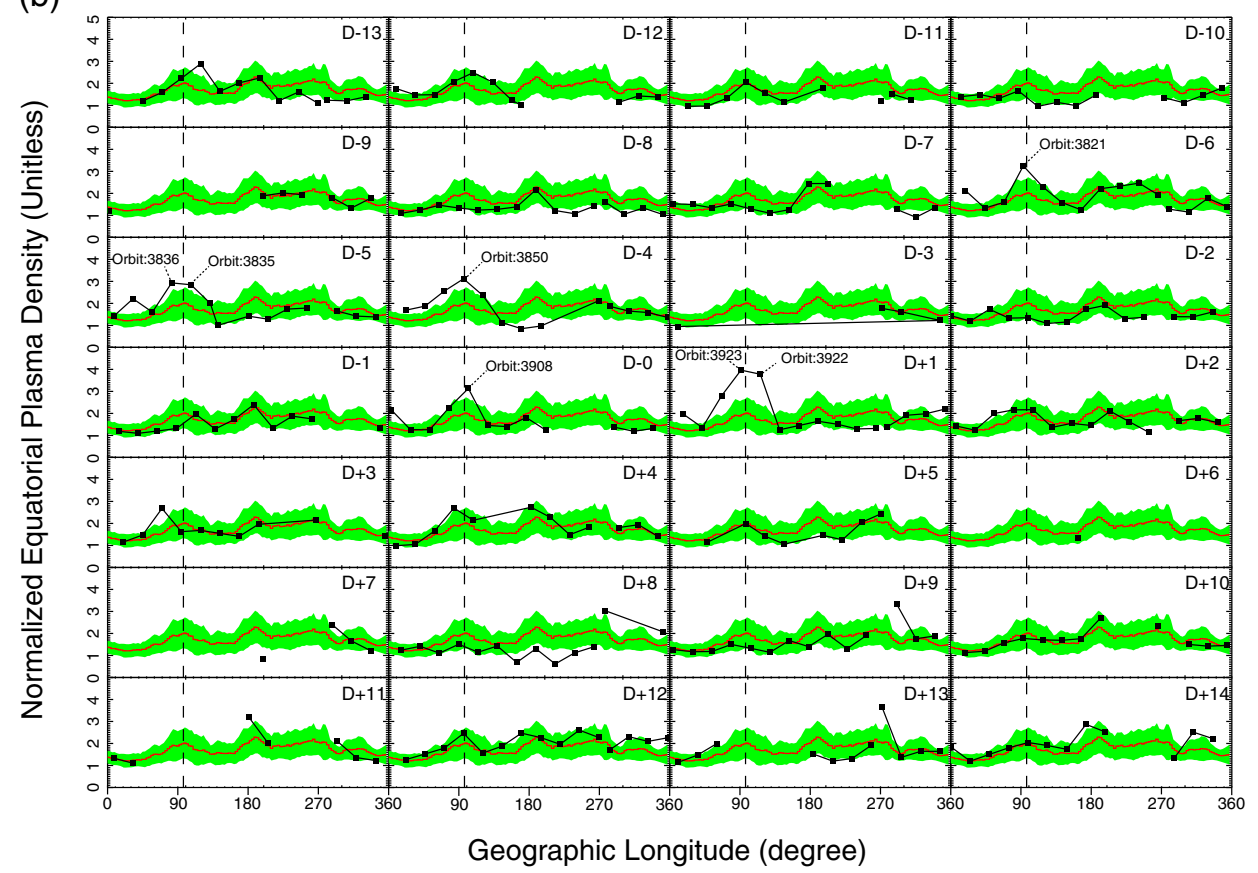

Figure 9. (a) Temporal variation of the NEPD of the DEMETER satellite passes whose longitudes are within $\pm 20^{\circ}$ from the epicenter and (b) the daily variation of the longitudinal distribution of the NEPD from $D-13$ to $D+14$ with respect to the main shock of the Sumatra earthquake.

Figure 9a. The NEPD values in the graph were filtered with the condition that the longitude of equatorial pass is within $20^{\circ}$ from that of the epicenter. The statistical reference was derived from the DEMETER measurements taken at the same season (March and April) of the consecutive years from 2006 to 2010 when the DEMETER satellite was operational. Throughout the period, the seismic activities were weaker than those of 2004 and 2005, when historic earthquakes occurred in the vicinity of Sumatra region.

As noted in the previous subsections, the EIA feature did not show apparent increase or decrease until about a week before the earthquake occurrence. Then the EIA intensity represented by NEPD increased above 3.0, which is larger than $1 \sigma$ range shown as green dashed lines, remained above it until 4 days before the shock, and then decreased within $1 \sigma$ range. The NEPD once again dramatically changed from a day before the earthquake $(D-1)$ to the next day of the main shock $(D+1)$. The NEPD returned to the $1 \sigma$ range with slight deviations afterward.

Figure $9 \mathrm{~b}$ shows the evolution of the longitudinal variations in the period from $D-13$ to $D+14$ within which the above mentioned anomalous increase took place in the orbits close to the epicenter. The red lines and green bands represent the averaged longitudinal variations and $1 \sigma$ ranges of the NEPD, respectively, derived from the same data set which was used for the derivation of the statistical reference in Figure 9a. The longitudinal variation derived from the reference data itself shows clear signature of wave- 4 structure. 


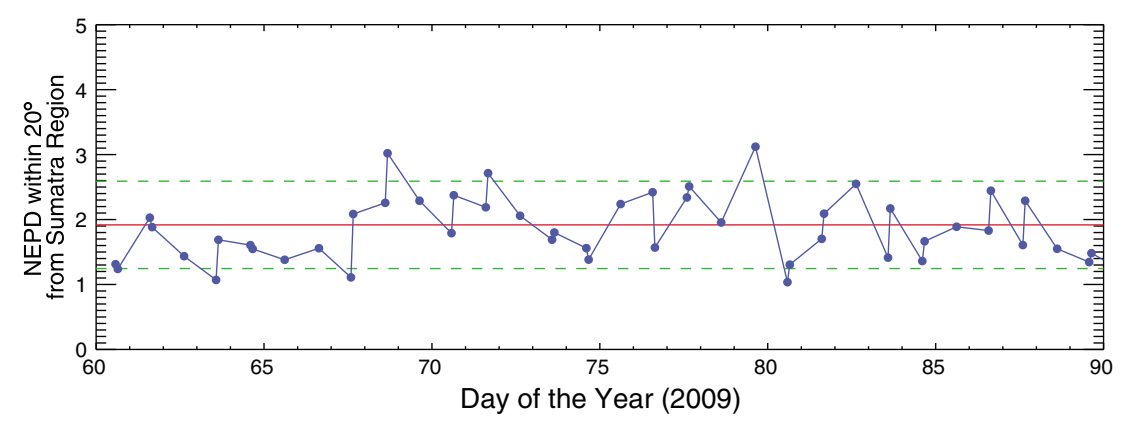

Figure 10. Temporal variation of the NEPD of the DEMETER satellite passes whose longitudes are within $\pm 20^{\circ}$ from the Sumatra region from March to April in the year of 2009.

Before $D-7$, most of the NEPD values, represented by solid squares, remain within $1 \sigma$ range of the longitudinal variation. At D-6, Orbit-3821 that passed the epicenter (vertical dashed lines) closely in longitude shows increase in the NEPD above 3.0, which is approaching $2 \sigma$ level. Increases above $1 \sigma$ level appeared again at $D-5, D-4, D-0$, and $D+1$, reaching the maximum $(\sim 3 \sigma)$ in the study period at Orbit-3923 at $D+1$. Then the longitudinal NEPD profile started to follow the statistical reference. At D+9 and D+13, there appeared increases in NEPD around $270^{\circ} \mathrm{E}$ but some of the data were missing as shown in the graphs making it difficult to perform unbiased analysis.

A notable feature that appears only in the orbits near which, in time, the increases in the NEPD near the epicenter were observed, is that the NEPD values at the eastside of the epicenter $\left(\sim 120^{\circ} \mathrm{E}-\sim 150^{\circ} \mathrm{E}\right)$ were reduced below the lower $1 \sigma$ range. An additional feature is that whenever the consecutive satellite passes close to the epicenter are available ( $D-5, D-4, D-0$, and $D+1)$, the westside from the epicenter have higher NEPD values. In short, the eastside passes from the epicenter show decreases in EIA intensity, expressed in NEPD, while the westside passes from the epicenter show increases in EIA intensity. This tendency of longitudinal change of EIA strength was also shown in the apex height distribution measured by CHAMP (see Figure 8a).

\section{Discussion}

\subsection{Comparisons With Other Examples}

The Sumatra Arc is one of the most seismically active regions in the equatorial area. During the DEMETER operation period, the spring of 2009 was remarked as the season when the seismic activity in the region was relatively calm. There were no earthquakes larger than M6.0 in the vicinity of the Sumatra Arc seismic zone. The space weather condition was also calm in that $D$ st remain larger than $-50 \mathrm{nT}$ and $K p$ index was less than 3.0 throughout the period.

Figure 10 shows the NEPD variation near the Sumatra Arc in longitude from March to April of 2009. As shown in the graph, the NEPD remain under 3.0. There were two cases when the NEPD approached 3.0 and they were thought to be related with geomagnetic activity.

There can exist fluctuations of the NEPD even if there are no strong earthquakes, mostly related with the space weather condition, which suggests that the seismic activity is not the only or the main driver of the EIA variation. Anyhow, while investigating the DEMETER ISL data, we could identify the similar example of the intensified ElA which is strongly thought to be related to a large earthquake since the temporal and spatial changes of the NEPD show very similar feature with those of the Sumatra earthquake.

The example is the case of M8.0 Pisco earthquake of 15 August 2007 (23:40:56 UTC). The earthquake also occurred in the equatorial region, while its location was near the coast of Central Peru $\left(13.36^{\circ} \mathrm{S}, 283.48^{\circ} \mathrm{E}\right)$. The depth of the hypocenter was $30.2 \mathrm{~km}$. The temporal and spatial variations of the EIA around the Pisco earthquake were shown in Figure 11, with the same method as that of Figure 9. We did not show the space weather condition within this period for the sake of simplicity. During the 3 months from July to September, the $D s t$ index did not exceed $-50 \mathrm{nT}$, which implies the geomagnetic activity was minimal in the period. In addition, we checked the peaks of the NEPD enhancements do not coincide with the increases of $K p$ index over 3.0. 
(a)

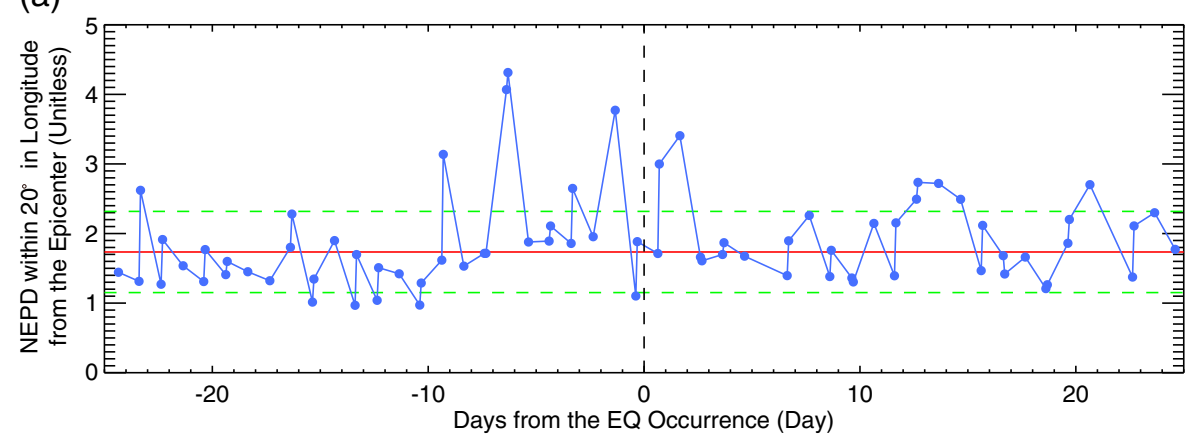

(b)

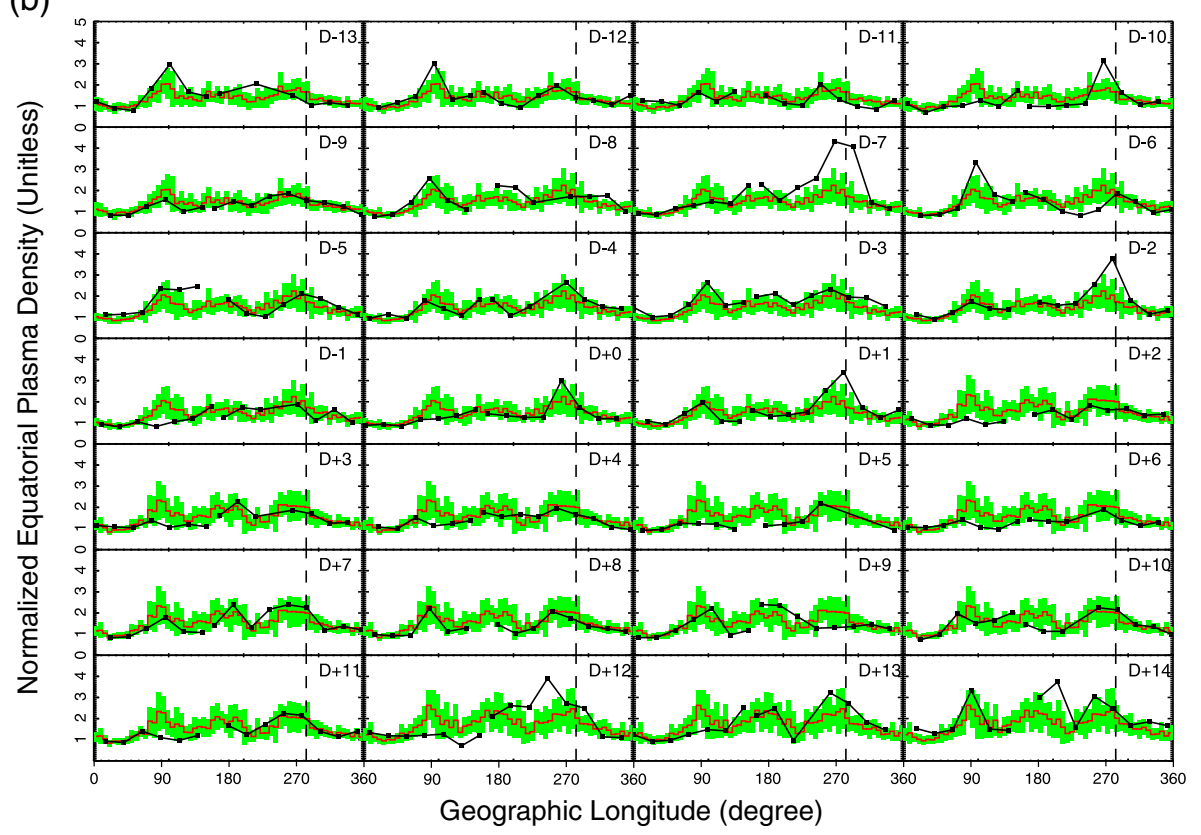

Figure 11. (a) Temporal variation of the NEPD of the DEMETER satellite passes whose longitudes are within $\pm 20^{\circ}$ from the epicenter and (b) the daily variation of the longitudinal distribution of the NEPD from D-13 to D+14 with respect to the Pisco earthquake of 2007.

Figure 11a shows the temporal evolution of the NEPD within $20^{\circ}$ in longitude from the Pisco earthquake. From about 10 days before the earthquake occurrence, the NEPD shows abrupt enhancements. The NEPD have maximum value at $D-7$ reaching 4.1 in Orbit-16571 and 4.3 in the successive orbit which are over $3 \sigma$ of the seasonal variation (green dashed lines). Then it returned to normal values until D-2. Again, it showed peaked increase over $2 \sigma$ from $D-2$ to $D+1$, then remained within $1 \sigma$ range.

The longitudinal variations of the NEPD day by day from $D-13$ to $D+14$ were shown in Figure $11 \mathrm{~b}$. As noted above, the most dramatic enhancements were observed on D-7 and the increments were observed only in two orbits whose longitudes are close to that of the epicenter of the Pisco earthquake, represented as a vertical dashed line. The reduction of NEPD in the east of the epicenter observed in the case of Sumatra earthquake did not appear clearly in the case of Pisco earthquake.

It is remarkable that the Sumatra earthquake was the largest earthquake (M8.7) in the year of 2005, while the Pisco earthquake was the largest earthquake (M8.0) among the earthquakes that occurred in the "Nazca Plate and South America" seismic zone [Rhea et al., 2010] in the year 2007. In addition, both the periods were relatively calm in geomagnetic activity.

\subsection{Were They Seismic Intensification of the Equatorial Ionization Anomaly?}

It was reported that there were increased ionospheric disturbances indicated by the crest $L$ value (CHAMP satellite) and the NEPD (DEMETER satellite) along the epicenter longitude within about a week before and 
after the northern Sumatra earthquake. Additionally, the case of Pisco earthquake was introduced which showed very similar behavior in the temporal and spatial variation of the NEPD derived from the DEMETER ISL measurements.

The disturbances observed in the ionospheric plasma density provided opportunities to investigate the underlying process of seismo-ionospheric coupling if it was the driver of the intensified EIA, since the features should vary according to the altitude and local time of the satellites. The observations cannot be called "direct evidence" of seismo-ionospheric coupling, nor earthquake precursory phenomena, since we could not provide evidence revealing all the processes happening in the lithosphere, the lower atmosphere, and the ionosphere as a whole. Instead, we might revise the current understanding of the seismo-ionosphere coupling to explain our observations, on the assumption that the observed features originated from seismic activities.

As shown in Figure 8a, the apex height of the EIA features derived from the electron density measurements of the CHAMP PLP were distributed from $\sim 400 \mathrm{~km}$ to $\sim 1200 \mathrm{~km}$, centered around $700-800 \mathrm{~km}$. Around (in both spatial and temporal vicinity) the northern Sumatra earthquake, $H_{\text {apex }}$ reached $\sim 1200 \mathrm{~km}$ implying that the driving force of the plasma uplift was reinforced around the seismic region. Oyama et al. [2011] reported that reductions in atomic oxygen and molecular ion densities observed by the U.S. satellite DE-2 around a large earthquake which occurred at the Chilean coast were similar to the EIA feature, but centered around the earthquake epicenter. They explained that this ion density reduction could be a superposition of a quiet time eastward electric field, and an electric field associated with the earthquake. The multisatellite observations of the ionospheric condition around the large earthquake in this study make it possible to definitize the current explanation of seismo-ionospheric coupling, especially in the low-latitude region.

As noted in the previous section, the EIA was intensified around the epicenter and the westward direction, while weakened in the eastward direction. If the phenomena were seismo-ionospheric coupling, the explanation could be found in the model suggested by Pulinets [2012]. He suggested that the ionospheric potential near the epicenter can either increase or decrease according to the decrease or increase in the atmospheric conductivity above the seismic zone by radon emanation. In the two cases, the observed EIA features near the northern Sumatra earthquake can be explained by the increased conductivity case. The schematic configuration of the seismo-ionospheric coupling, adopted from Pulinets [2012], was shown in Figure 12a. In case of the increased conductivity near the Earth's surface, the ionospheric potential decreases and, thus, the inward electric field is generated. Since the magnetic field lines are near parallel to the Earth's surface in the equatorial region, only the zonal electric field take effect as shown. In combination with the eastward zonal electric field in the dayside ionosphere, the upward drift velocity is enhanced in the west and reduced in the east of the epicenter.

The meridional views at each side of the epicenter were shown in Figures 12b and 12c. The eastward electric field was depicted as a dotted circle in the cartoon implying that the direction is outward from the paper. Due to the high conductivity parallel to the Earth's magnetic field, the perpendicular electric field at ionospheric heights would be transmitted along the magnetic field lines. In addition to this, the eastward component electric field developed above the west of the epicenter region would be transferred parallel along the geomagnetic field lines (depicted as a thick dashed line), and expected to have a symmetric feature in the region of its geomagnetic conjugate. The downward diffusion of the plasma along the dipole magnetic field lines is accompanied by symmetrical poleward drift generating crest/trough density profiles at the CHAMP altitude. In the east of the epicenter, the direction of the seismically generated $E$ field is reversed so that the altitude at which the plasma can be drifted is reduced as shown in Figure 12c.

There are still debates about the mechanism by which the electric field around the epicenter is created, so that more observational and experimental evidence is required. The results of our study are not directly related to the electric field or the charge creation mechanism. However, Freund [2010] noted that positive holes generated by squeezed rocks in the seismic preparation zone can change the electric potential of the atmosphere and the ionosphere. In addition, Orihara et al. [2012] reported the existence of the preseismic anomalous, telluric current signals, and their correlation with seismic activities on Kozu-shima Island. Their results could be thought of as indirect evidence that seismo-ionospheric coupling could be triggered by the lithospheric current and the charge collection mechanism. 


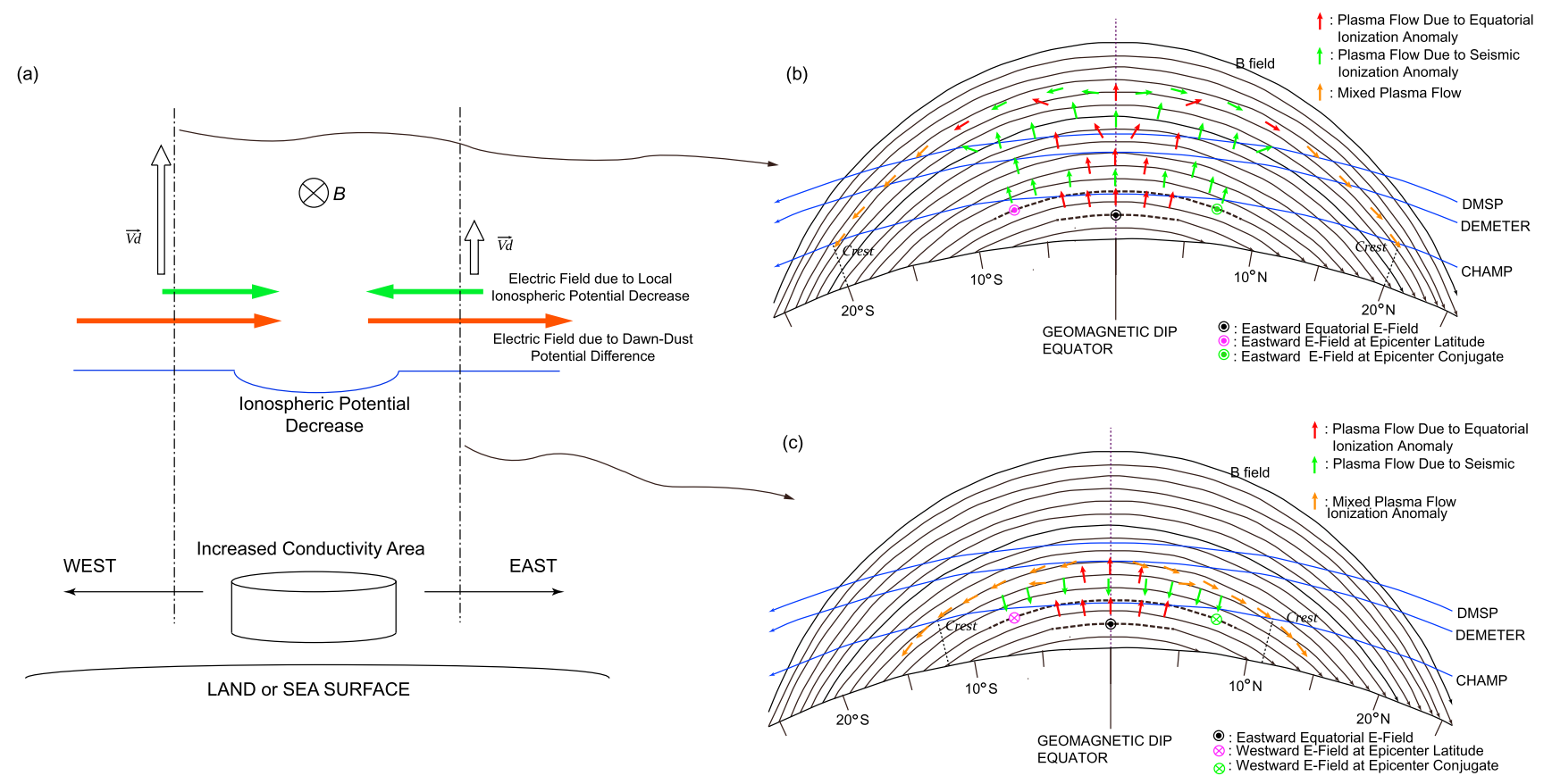

Figure 12. (a) Schematic cartoons showing the seismo-ionospheric coupling adopted from [Pulinets, 2012], which can explain the observed ElA variation. ( $b$ and c) Meridional views in the west and the east of the epicenter, respectively. The geomagnetic field lines and the Earth radius were drawn according to the dipole approximation to scale. The red, green, and orange arrows represent the plasma flows due to the natural ElA, due to seismic effect, and due to mixed flows, respectively. The orbits of three satellites are shown with blue lines. The eastward electric field which drives the quiet time ElA is represented by black dotted circles, while the eastward/westward seismic electric fields at the epicenter and its geomagnetic conjugate latitude were shown with pink and green dotted/crossed circles. The presumed electric fields transferred parallel along the geomagnetic field lines were depicted as thick dashed lines.

Since the whole Sunda Trench and majority of epicenters of earthquakes presented in the Table 1 are under water, it is questionable how the electric charges could penetrate to the ocean surface. Ondoh [2003] explained that radon gas would emanate from the ground, including land and sea surfaces [Pulinets, 2012], to significantly ionize the air and that the radioactive decay of radon atoms through high-energy alpha particle emission can cause the formation of ion pairs and thus increase air conductivity. The processes of surface charging and atmospheric ionization can cooperatively trigger an upward electric current over the seismoactive region and form a horizontal electric field at the bottom of the ionosphere [Kuo et al., 2011]. Due to the apparition of electrical charges, the air conductivity at the Earth's surface is modified and the consequent change for the ionospheric potential was described by Rycroft et al. [2008]. Harrison et al. [2010, 2014] have presented an application of this mechanism to earthquake processes. Pulinets and Ouzounov [2011] presented a Lithosphere-Atmosphere-Ionosphere Coupling model to explain the precursory phenomena of earthquakes. According to them, radon is emanated from the Earth's crust continuously, even without earthquakes, and the deviated radon emission in the earthquake preparation period results in the ionospheric potential in the vicinity of the epicenter. Even, they pointed out that the anomalous radon activity stops immediately or within a few days after the main shock, which is remarkably consistent with our observations around the Sumatra earthquake of March 2005 and the Pisco earthquake of August 2007.

Stolle et al. [2008] derived an empirical relation between the EIA apex height, $H_{\text {apex }}$ (in kilometer), and the eastward electric field, $E_{y}$ (in $\mathrm{mV} / \mathrm{m}$ ), as follows:

$$
H_{\text {apex }}=516 \mathrm{~km}+512 \frac{\mathrm{km}}{\mathrm{mV} / \mathrm{m}} E_{y} .
$$

If we apply our observed EIA parameters of Sumatra earthquake case, to this empirical relation, we could state that the eastward electric field of $\sim 0.55 \mathrm{mV} / \mathrm{m}$; under the usual EIA condition $\left(H_{\text {apex }}=\sim 800 \mathrm{~km}\right)$, increased to $\sim 1.34 \mathrm{mV} / \mathrm{m}$; when the EIA is thought to have been increased by seismic activities $\left(H_{\text {apex }}=\right.$ $\sim 1200 \mathrm{~km}$ ). Accordingly, a $\sim 0.8 \mathrm{mV} / \mathrm{m}$ increase can be attributed purely to the seismic activities. The ElA crest locations due to (1) the usual equatorial eastward $E$ field, (2) the eastward $E$ field at the epicenter and its conjugate, and (3) the net $E$ field of (1) and (2) are $\pm 20^{\circ}, \pm 22.5^{\circ}$, and $\pm 27^{\circ}$, in geomagnetic latitude. Since 
the geomagnetic field lines are fairly inclined at the locations of the crests due to the net $E$ field, there should be an equatorward (or less poleward) neutral wind for the electron density to increase at these EIA crest locations [Balan et al., 2013]. It would be natural to think that the electric field intensity formed by the seismic effects has a positive correlation with the earthquake magnitude, but we lack observational evidences to prove this postulate. However, it is worthy of note that Kuo et al. [2011] estimated that an electric field of $\sim 1 \mathrm{mV} / \mathrm{m}$ at $85 \mathrm{~km}$ can be produced by current density $J_{\text {rock }}=1.4 \mu \mathrm{A} / \mathrm{m}^{2}$ for daytime conductivity.

\section{Summary and Conclusions}

We investigated the ionospheric conditions spatially and temporally surrounding the northern Sumatra earthquake that occurred on 28 March 2005. The ionospheric parameters on the dayside measured by the DEMETER, CHAMP, and DMSP satellites at various altitudes were used in the analyses.

We observed that the EIA features that usually existed throughout the study period ( 2 months around the main earthquake) were intensified along the orbits whose longitudes were close to the epicenter, before and after the main shock. We derived the crest $L$ values and the apex heights, which represent the intensity of the EIA, for all the orbits of the CHAMP satellite within the study period, to quantify the ionospheric changes that might be correlated with the seismic activities. We also found that the NEPD, which quantify the equatorial $\left( \pm 15^{\circ}\right.$ in geomagnetic latitude) electron density relative to the midlatitude density observed by the DEMETER satellite, also increased in the spatial and temporal vicinity of the earthquake event. The apex height enhancements along the orbits with longitudes relatively close to the epicenter observed in the CHAMP plasma measurements started about a week before the earthquake and continued until about a week after the earthquake, suggesting the phenomena were possibly caused by the seismic activity. In the case of the NEPD derived from the DEMETER satellite, increases in the parameter were observed from about a week before, to a day after, the earthquake, reaching maximum a day after the earthquake, and diminished afterward. The upward plasma drift were enhanced in the westward from the epicenter and reduced in the eastward direction, which is consistent with one of the previously suggested seismo-ionospheric coupling models of ionospheric potential decrease. In addition, similar EIA enhancements appeared in the NEPD related to the M8.0 Pisco earthquake of 15 August 2007. The questions still remain whether the increases can be clearly separated and distinguished from the wave structure, of which density crests are known to be caused by atmospheric tidal effects, or that these increases accidentally coincided with the most frequent earthquake occurrence along the geomagnetic equator.

Based on the assumption that the observed EIA increases originated from seismo-ionospheric coupling, the multisatellite observations from various altitudes were applied to revise the current understanding of the mechanism by which the equatorial ionosphere is affected by seismic activities. More observational evidence and theoretical studies are required to reach a unanimous explanation of the overall processes and the underlying mechanisms, of seismo-ionosphere coupling, and of its correlation with EIA features.

Acknowledgments

This work was supported by grant CATER2012-5060 from the Center for Atmospheric Science and Earthquake Research (CATER) in Korea. We are grateful to the engineers and scientists who were involved in the developments, operations, and data processes of the DEMETER, CHAMP, and DMSP satellites. We also thank $\mathrm{H}$. Kil at Johns Hopkins University Applied Physics Laboratory, J. J. Berthelier at LATMOS/ISSL, and J. P. Lebreton at LPC2E/CNRS for valuable comments on the behavior of the equatorial ionosphere and the data validity of the IAP and ISL.

Robert Lysak thanks Sergey Pulinets and two anonymous reviewers for their assistance in evaluating this paper.

\section{References}

Anderson, D. N. (1981), Modeling the ambient, low latitude F-region ionosphere-A review, J. Atmos. Terr. Phys., 43, $753-762$. Appleton, E. V. (1954), The anomalous equatorial belt in the F2-layer, J. Atmos. Terr. Phys., 5, 348-351.

Balan, N., Y. Otsuka, M. Nishioka, J. Y. Liu, and G. J. Bailey (2013), Physical mechanisms of the ionospheric storms at equatorial and higher latitudes during the recovery phase of geomagnetic storms, J. Geophys. Res. Space Physics, 118, 2660-2669, doi:10.1002/jgra.50275.

Berthelier, J. J., M. Godefroy, F. Leblanc, E. Seran, D. Peschard, P. Gilbert, and J. Artru (2006), IAP, the thermal plasma analyzer on DEMETER, Planet. Space Sci., 54(5), 487-501, doi:10.1016/j.pss.2005.10.017.

Coley, W. R., R. A. Heelis, M. D. Perdue, and R. A. Power (2010), lonospheric monitoring and specification utilizing data from the defense meteorological satellite program, Sci. Rep., Univ. of Texas at Dallas, Richardson, Tex.

Cussac, T., M.-A. Clair, P. Ultré-Guerard, F. Buisson, G. Lassalle-Balier, M. Ledu, C. Elisabelar, X. Passot, and N. Rey (2006), The DEMETER microsatellite and ground segment, Planet. Space Sci., 54, 413-427, doi:10.1016/j.pss.2005.10.013.

England, S. L., S. Maus, T. J. Immel, and S. N. Mende (2006), Longitudinal variation of the E-region electric field caused by atmospheric tides, Geophys. Res. Lett., 33, L21105, doi:10.1029/2006GL027465.

Freund, F. (2010), Toward a unified solid state theory for pre-earthquake signals, Acta Geophys., 58(5), 719-766, doi:10.2478/s11600-009-0066-x.

Fujiwara, H., M. Kamogawa, M. Ikeda, J. Y. Liu, H. Sakata, Y. I. Chen, H. Ofuruton, S. Muramatsu, Y. J. Chuo, and Y. H. Ohtsuki (2004), Atomospheric anomalies observed during earthquake occurrences, Geophys. Res. Lett., 31, L17110, doi:10.1029/2004GL019865.

Gutenberg, B., and C. F. Richter (1956), Magnitude and energy of earthquakes, Ann. Geofis., 9, 1-15.

Harrison, R. G., K. L. Aplin, and M. J. Rycroft (2010), Atmospheric electricity coupling between earthquake regions and the ionosphere, J. Atmos. Sol. Terr. Phys., 72, 376-381, doi:10.1016/j.jastp.2009.12.004.

Harrison, R. G., K. L. Aplin, and M. J. Rycroft (2014), Brief communication: Earthquake-cloud coupling through the global atmospheric electric circuit, Nat. Hazards Earth Syst. Sci., 14, 773-777, doi:10.5194/nhess-14-773-2014. 
Hayakawa, M., O. A. Molchanov, T. Kodama, V. V. Afonin, and O. A. Akentieva (2000), Plasma density variations observed on a satellite possibly related to seismicity, Adv. Space Res., 28, 1277-1280, doi:10.1016/S0273-1177(99)01224-7.

Heelis, R. A. (2006), Post-launch support for DMSP SSIES sensors, Final Rep., AFRL-VS-HA-TR-2007-1006, Air Force Research Laboratory, Tex. Immel, T. J., E. Sagawa, S. L. England, S. B. Henderson, M. E. Hagan, S. B. Mende, H. U. Frey, C. M. Swenson, and L. J. Paxton (2006), Control of equatorial ionospheric morphology by atmospheric tides, Geophys. Res. Lett., 33, L15108, doi:10.1029/2006GL026161.

Kil, H., E. R. Tallat, S.-J. Oh, L. J. Paxton, S. L. England, and S.-Y. Su (2008), Wave strcture of the plasma density and vertical EXB drift in low-latitude F region, J. Geophys. Res., 113, A09312, doi:10.1029/2008JA013106.

Kuo, C. L., J. D. Huba, G. Joyce, and L. C. Lee (2011), lonosphere plasma bubbles and density variations induced by pre-earthquake rock currents and associated surface charges, J. Geophys. Res., 116, A10317, doi:10.1029/2011JA016628.

Lebreton, J.-P., et al. (2006), The ISL Langmuir probe experiment processing onboard DEMETER: Scientific objectives, description and first results, Planet. Space Sci., 54(5), 472-486, doi:10.1016/j.pss.2005.10.017.

Li, M., and M. Parrot (2013), Statistical analysis of an ionospheric parameter as a base for earthquake prediction, J. Geophys. Res. Space Physics, 118, 3731-3739, doi:10.1002/jgra.50313.

Liu, H., and S. Watanabe (2008), Seasonal variation of the longitudinal structure of the equatorial ionosphere: Does it reflect tidal influences from below?, J. Geophys. Res., 113, A08315, doi:10.1029/2008JA013027.

Liu, J. Y., Y. I. Chen, Y. J. Chuo, and C. S. Chen (2006), A statistical investigation of preearthquake ionospheric anomaly, J. Geophys. Res., 111, A05304, doi:10.1029/2005JA011333.

Liu, J. Y., H. Le, Y. I. Chen, L. Liu, W. Wan, Y. Z. Su, Y. Y. Sun, C. H. Lin, and M. Q. Chen (2011), Observations and simulations of seismoionospheric GPS total electron content anomalies before the 12 January 2010 M7 Haiti earthquake, J. Geophys. Res., 116, A04302, doi:10.1029/2010JA015704.

Lühr, H., J. Park, P. Ritter, and H. Liu (2012), In-situ CHAMP observation of ionosphere-thermosphere coupling, Space Sci. Rev., 168, 237-260, doi:10.1007/s11214-011-9798-4.

Manoj, C. S. M., H. Lühr, and P. Alken (2008), Penetration characteristics of the interplanetary electric field to the daytime equatorial ionosphere, J. Geophys. Res., 113, A12310, doi:10.1029/2008JA013381.

McNamara, L. F., D. L. Cooke, C. E. Valladares, and B. W. Reinisch (2007), Comparison of CHAMP and Digisonde plasma frequencies at Jicamarca, Peru, Radio Sci., 42, RS2005, doi:10.1029/2006RS003491.

Mendillo, M., B. Lin, and J. Aarons (2000), The application of GPS observations to equatorial aeronomy, Radio Sci., 35(3), 885-904, doi:10.1029/1999RS002208.

Namgaladze, A. A., M. V. Klimenko, V. V. Klimenko, and I. E. Zakharenkova (2009), Physical mechanism and mathematical modeling of earthquake ionospheric precursors registered in total electron content, Geomagn. Aeron., 49(2), 252-262, doi:10.1134/S0016793209020169.

Ondoh, T. (2003), Anomalous sporadic-E layers observed before M7.2 Hyogo-ken Nanbu earthquake; Terrestrial gas emanation model, Adv. Polar Upper Atmos. Res., 17, 96-108.

Orihara, Y., M. Kamogawa, T. Nagao, and S. Uyeda (2012), Preseismic anomalous telluric current signals observed in Kozu-shima Island, Japan, Proc. Natl. Acad. Sci., 109(47), 19,125-19,128, doi:10.1073/pnas.1215669109.

Oyama, K.-I., Y. Kakinami, J. Y. Liu, M. Kamogawa, and T. Kodama (2008), Reduction of electron temperature in low-latitude ionosphere at $600 \mathrm{~km}$ before and after large earthquakes, J. Geophys. Res., 113, A11317, doi:10.1029/2008JA013367.

Oyama, K.-I., Y. Kakinami, J. Y. Liu, M. A. Abdu, and C. Z. Cheng (2011), Latitudinal distribution of anomalous ion density as a precursor of a large earthquake, J. Geophys. Res., 116, A04319, doi:10.1029/2010JA015948.

Parrot, M. (2002), The micro-satellite DEMETER, J. Geodyn., 33, 535-541, doi:10.1016/S0264-3707(02)00014-5.

Pedatella, N. M., and J. M. Forbes (2011), Electrodynamic response of the ionosphere to high-speed solar wind streams, J. Geophys. Res., 116, A12310, doi:10.1029/2011JA017050.

Pulinets, S. (2012), Low-latitude atmosphere-ionosphere effects initiated by strong earthquakes preparation process, Int. J. Geophys., 2012, 131,842, doi:10.1155/2012/131842.

Pulinets, S., and K. Boyarchuk (2004), lonospheric Precursors of Earthquakes, 1st ed., Springer, Berlin, Germany.

Pulinets, S., and D. Ouzounov (2011), Lithosphere-Atmosphere-lonosphere Coupling (LAIC) model—An unified concept for earthquake precursors validation, J. Asian Earth Sci., 41, 371-382, doi:10.1016/j.jseaes.2010.03.005.

Pulinets, S. A., A. D. Legen'ka, and V. H. Depuev (2000), Pre-seismic activity effects on the equatorial anomaly, in International Symposium on Equatorial Aeronomy, pp. 4-11, ISEA-10, Antalya, Turkey.

Ren, Z., W. Wan, L. Liu, R. A. Heelis, B. Zhao, Y. Wei, and X. Yues (2009), Influences of geomagnetic fields on longitudinal variations of vertical plasma drifts in the presunset equatorial topside ionosphere, J. Geophys. Res., 114, A03305, doi:10.1029/2008JA013675.

Rhea, S., G. Hayes, A. Villaseñor, K. P. Furlong, A. C. Tarr, and H. M. Benz (2010), Seismicity of the Earth 1900-2007, U.S. Geol. Surv. Open-File Rep., 2010-1083-E, 1 map sheet, scale 1:12,000,000. [Available at http://pubs.usgs.gov/of/2010/1083/e/.]

Ruzhin, Y. Y., V. I. Larkina, and A. K. Depueva (1998), Earthquake precursors in magnetically conjugated ionosphere regions, Adv. Space Res., 21(3), 525-528.

Rycroft, M. J., R. G. Harrison, K. A. Nicoll, and E. A. Mareev (2008), An overview of Earth's global electric circuit and atmospheric conductivity, Space Sci. Rev., 137, 83-105, doi:10.1007/s11214-008-9368-6.

Sagawa, E., T. J. Immel, H. U. Frey, and S. B. Mendes (2005), Longitudinal structure of the equatorial anomaly in the nighttime ionosphere observed by IMAGE/FUV, J. Geophys. Res., 110, A11302, doi:10.1029/2004JA010848.

Stolle, C., C. Manoj, H. Lühr, S. Maus, and P. Alken (2008), Estimating the daytime equatorial ionization anomaly strength from electric field proxies, J. Geophys. Res., 113, A09310, doi:10.1029/2007JA012781.

Tsurutani, B. T., and W. D. Gonzalez (1987), The cause of high-intensity long-duration continuous AE activity (HILDCAA): Interplanetary Alfvén wave train, Planet. Space Sci., 35, 405-412, doi:10.1016/0032-0633(87)90097-3.

Walker, G. O., J. H. K. Ma, and E. Golton (1994), The equatorial ionospheric anomaly in electron content from solar minimum to solar maximum for South East Asia, Ann. Geophys., 12, 195-209.

West, K. H., and R. A. Heelis (1996), Longitude variations in ion composition in the morning and evening topside equatorial ionosphere near solar minimum, J. Geophys. Res., 101, 7951-7960, doi:10.1029/95JA03377. 